\title{
VARIABLES ASOCIADAS AL COMPORTAMIENTO DE LOS INGRESOS POR VENTAS EN LAS PRINCIPALES PLAZAS DE MERCADO DE POPAYÁN, COLOMBIA*
}

\author{
Recibido: 19 de enero del 2018 • Aprobado: 15 de octubre del 2018 \\ https://doi.org/10.22395/seec.v21n49a5 \\ Claudia Liceth Fajardo Hoyos* \\ Andrés Mauricio Gómez Sánchez** \\ Juliana Isabel Sarmiento Castillo
}

\section{RESUMEN}

El objetivo del artículo es analizar cómo se relacionan los factores socioeconómicos, características de los negocios y aspectos institucionales con los niveles de ingresos por ventas de los comerciantes, tanto formales como informales, de las plazas de mercado de los barrios Bolívar y la Esmeralda en la ciudad de Popayán, Colombia. Para ello, se utilizó un modelo estocástico de regresión cuantílica con logaritmos. Los resultados muestran que factores como género y edad disminuyen los ingresos, pero otros como acceso a créditos formales los aumenta, no obstante, el apoyo institucional impacta de forma diferente en ambas plazas de mercado o galerías.

\section{PALABRAS CLAVES}

Bienestar; economía informal; economía regional; regresión cuantílica.

\section{CLASIFICACIÓN JEL}

I31, E26, R58, C31

\section{CONTENIDO}

Introducción; 1. Marco teórico y estudios aplicados; 2. Aspectos socioeconómicos de los comerciantes de las plazas de mercado de los barrios Bolívar y La Esmeralda de la ciudad de Popayán; 3. Análisis estadístico; 4. Resultados; 5. Conclusiones y recomendaciones; Bibliografía.

Este artículo es el resultado de dos estudios realizados por el Observatorio Regional del Mercado de Trabajo (Ormet) Popayán (2016), titulados: "Estudio socioeconómico de la plaza de mercado del Barrio Bolívar" y "Estudio de socioeconómico de la plaza de mercado del barrio La Esmeralda", financiados por la Alcaldía Municipal y el Ministerio de Trabajo. Los autores agradecen el apoyo financiero de dichas entidades.

* Economista, Universidad del Valle. Magíster en Economía Aplicada, Universidad del Valle. Estudiante de Doctorado en Economía de los Negocios, Universidad Icesi. Docente del Departamento de Economía, Universidad del Cauca. Miembro del Grupo de Investigación Entropía, Universidad del Cauca. Dirección: Calle 5 No. 4-70, Universidad del Cauca. Correo electrónico: cfajardo@unicauca.edu.co

... Economista, Universidad del Valle. Especialista en Gerencia de Proyectos, Universidad del Cauca Magíster en Economía Aplicada, Universidad del Valle. Estudiante de Doctorado en Economía Industrial, Universidad de Valencia, España. Docente del Departamento de Economía, Universidad del Cauca. Miembro del Grupo de Investigación Entropía, Universidad del Cauca. Dirección: Calle 5 No. 4-70, Universidad del Cauca. Correo electrónico: amgomez@unicauca.edu.co

.... Economista, Universidad del Cauca. Especialista en Finanzas, Universidad del Valle. Doctora en Ciencias Ambientales, Universidad del Cauca. Docente del Departamento de Economía, Universidad del Cauca. Miembro del Grupo de Investigación Entropía, Universidad del Cauca. Dirección: Calle 5 No. 4-70, Universidad del Cauca. Correo electrónico: jisarmiento@unicauca.edu.co 


\title{
VARIABLES ASSOCIATED TO SALES INCOME BEHAVIOR IN THE MAIN MARKET SQUARES OF POPAYÁN, COLOMBIA
}

\begin{abstract}
The paper's objective is to analyze how socioeconomic factors are related, businesses characteristics and institutional aspects with the sales income levels of merchants, both formal and informal, of the market squares of the Bolívar and La Esmeralda neighborhoods of the city of Popayán, Colombia. To do this, a stochastic quantile regression model with logarithms was used. Results show that factors such as gender and age decrease income, but others such as access to formal credits increase them; however, institutional support impacts differently in both market places or squares.
\end{abstract}

\section{KEYWORDS}

Wellness; informal economy; regional economy; quantile regression.

\section{JEL CLASSIFICATION}

I31, E26, R58, C31

\section{CONTENTS}

Introduction; 1. Theoretical framework and applied studies; 2. Socioeconomic aspects of merchants of the market squares of the Bolívar and La Esmeralda neighborhoods of the city of Popayán; 3. Statistical analysis; 4. Results; 5. Conclusions and recommendations; Bibliography.

\section{VARIÁVEIS ASSOCIADAS AO COMPORTAMENTO DOS GANHOS POR VENDAS NOS PRINCIPAIS MERCADOS MUNICIPAIS DE POPAYÁN, COLÔMBIA}

\section{RESUMO}

O objetivo do artigo é analisar como se relacionam os fatores socioeconômicos, as características dos negócios e os aspectos institucionais com os níveis de ganhos por vendas dos comerciantes, tanto formais quanto informais, dos mercados municipais dos bairros Bolívar e La Esmeralda na cidade de Popayán, Colômbia. Para isso, utilizou-se um modelo estocástico de regressão quantílica com logaritmos. Os resultados mostram que fatores como gênero e idade diminuem os ganhos, mas outros, como o acesso a créditos formais, aumentam os ingressos. Não obstante, o apoio institucional impacta de forma diferente em ambos os mercados municipais ou galerias.

\section{PALAVRAS-CHAVE}

Bem-estar; economia informal; economia regional; regressão quantílica.

\section{CLASSIFICAÇÃO JEL}

I31, E26, R58, C31

\section{CONTEÚDO}

Introdução; 1. Enquadramento teórico e estudos aplicados; 2. Aspectos socioeconômicos dos comerciantes dos mercados municipais dos bairros Bolívar e La Esmeralda na cidade de Popayán; 3. Análise estatística; 4. Resultados; 5. Conclusões e recomendações; Bibliografia. 
Variables asociadas al comportamiento de los ingresos por ventas en las principales plazas de mercado de Popayán, Colombia

\section{INTRODUCCIÓN}

La incapacidad que tiene el mercado laboral para absorber la diversidad de la oferta de mano de obra en Colombia ha generado, como en otros países de la región, que individuos, grupos, o comunidades busquen alternativas económicas que las permitan cubrir sus necesidades básicas diarias y que les garanticen un nivel de vida mínimo. Una de estas alternativas es la informalidad, un fenómeno crítico para el país puesto que, por un lado, los salarios de la población se reducen, lo cual hace más vulnerable a las personas en cuestión y a sus familias frente a la pobreza y por consiguiente, compromete su calidad de vida; y de otro lado, las altas tasas de informalidad no permiten garantizar los recursos suficientes que sostener el sistema pensional.

En términos regionales, en el 2016 el departamento del Cauca se ubicó 5 puestos por debajo del promedio nacional y Popayán su capital, es la $6^{\circ}$ ciudad con más alto nivel de desempleo en el país, con un 12,6\% en el trimestre marzo-junio del 2017. La informalidad laboral en Popayán para ese mismo periodo lo representaron un $57,9 \%$ de los ocupados.

Una de las alternativas a este problema de absorción del mercado laboral es la economía popular, que de acuerdo con Sarria y Tiribia (2004, p. 173), se define como "el conjunto de actividades económicas y prácticas sociales desarrolladas por los sectores populares con miras a garantizar, a través de la utilización de su propia fuerza de trabajo y de los recursos disponibles, la satisfacción de las necesidades básicas, tanto materiales como inmateriales". Estas prácticas no se deben confundir con la economía informal o del rebusque, pues a diferencia de ellas, no se produce solo para la obtención de ganancias monetarias individuales, va más allá, pues que supone operar de forma cooperativa o colectiva, se crean y comparten no solo experiencias, sino también saberes, aspectos culturales y sociales. En este sentido, son prácticas sociales y económicas que se salen de la visión individualista y egoísta del capitalismo y por ende de toda la racionalidad económica ortodoxa.

Una de las manifestaciones de economía popular más visible en Colombia se encuentra dentro de las plazas de mercado de gran tamaño, conocidas como galerías, las cuales, si bien están conformadas por vendedores que intentan procurarse una ganancia diaria, también lo están por comunidades de diversa índole que van más allá del beneficio monetario, al operar en red y de forma solidaria por el bienestar de sus similares. Ejemplo de ello son las galerías del barrio Bolívar y La Esmeralda, ubicadas en la ciudad de Popayán, en las que no solo confluyen vendedores comunes sino también familiares, amigos, campesinos, comunidades indígenas y desplazados del conflicto armado, cuyo objetivo estriba en mejorar sus condiciones de vida. 
La galería del barrio Bolívar es la más grande e importante de la ciudad, no solo por ser la más antigua, ya que data de 1537; sino también porque de acuerdo con este estudio, alberga a más de 1.300 comerciantes y genera alrededor de 4.000 millones de pesos al mes. La plaza de mercado del barrio La Esmeralda comenzó a operar en 1967, actualmente cuenta con alrededor de 1.023 comerciantes que abastecen con productos de todo tipo al sector occidental de Popayán.

La dinámica comercial, originada por el aumento de la población y las crecientes migraciones a la capital caucana (proveniente de zonas rurales y de otras partes urbanas) han ido cobrando importancia. Dicho incremento propicia un aumento del empleo informal, puesto que este sector se presenta como receptor propicio para la fuerza laboral que no se logra insertar en el sector formal local'. Por tanto, es en este tipo de escenarios que una gran cantidad de vendedores buscan un ingreso inmediato, como una alternativa de fácil acceso.

En este orden de consideraciones, este documento tiene como objetivo analizar los factores socioeconómicos y comerciales asociados a los niveles de ingresos de los vendedores de las galerías del barrio Bolívar y La Esmeralda. Para ello, este estudio se divide en cinco apartados. Luego de la introducción a la problemática a tratar se construye un marco teórico y aplicado relacionado con el tema del objeto de estudio; le sigue un análisis descriptivo comparativo de las condiciones de los comerciantes de ambas galerías. A continuación, se implementa un modelo econométrico que muestra la relación entre variables socioeconómicas, comerciales e institucionales con el cambio relativo de los ingresos, y finaliza con unas conclusiones y recomendaciones.

\section{MARCO TEÓRICO Y ESTUDIOS APLICADOS}

De acuerdo con Katz y Stumpo (2001), la dinámica de los mercados laborales capitalistas actuales cada vez exige -desde la perspectiva de la oferta- niveles de cualificación, experiencia y competencias blandas mayores, debido a que la productividad de los trabajadores es uno de los motores que impulsa la competencia y por ende los beneficios económicos. Del lado de la demanda, López, Ávila y Méndez (2011) argumentan que los mercados laborales muestran que la capacidad de absorción de los trabajadores es cada vez más baja en las actuales condiciones del capitalismo, ya que existe un desequilibrio entre el tipo de trabajadores que requieren los empresarios y el tipo de trabajadores que buscan trabajo.

Popayán es una de las ciudades que afronta uno de los mayores índices de desempleo del país, de acuerdo con el Departamento Administrativo Nacional de Estadística (DANE) alcanza un promedio trimestral del $17,9 \%$ entre el 2007 y el 2015. 
Variables asociadas al comportamiento de los ingresos por ventas en las principales plazas de mercado de Popayán, Colombia

En consonancia con lo anterior, Coraggio (2010, p. 1) manifiesta que, "la creciente incapacidad del modelo neoliberal de mercado para resolver la cuestión social que genera [...] ha venido profundizando una crisis de reproducción de la vida humana, generando una pérdida de legitimidad del sistema de mercado global y espacio para acciones correctivas desde el Estado o la Sociedad". El punto fundamental aquí es que el mismo mercado se encarga de propiciar la desigualdad social entre aquellos que pueden acceder y los que quedan al margen, situación que se agudiza en el ámbito regional. Como lo expresa Hurtado (2013, p. 18): "América Latina se enfrenta al debilitamiento progresivo de sus economías, sus mercados internos no son tan fuertes y los problemas estructurales se sienten intensamente cuando la tendencia es hacia la desigualdad social".

Las investigaciones sobre las dinámicas en las plazas de mercado en diferentes países, a pesar de tratar temas variados, tienen un común denominador: la problemática social vinculada a ellas, puesto que se considera que la actividad de la plaza de mercado encadena algunos conflictos. La problemática social puede recibir intervención de los actores en forma de organización comunal, en cuanto a que se encadenen procesos dialécticos para la identificación y resolución de problemas, de tal manera que se genere una participación horizontal en la toma de decisiones y que se manejen de manera adecuada los nuevos conflictos que puedan emerger.

Sin embargo, en la presente investigación se considera oportuna una intervención estatal de la Alcaldía Municipal de Popayán, puesto que las instituciones formales e informales están sujetas a costos de transacción que se deben reducir o desaparecer mediante la intervención oficial, de acuerdo con North (1998). Así mismo, se debe distinguir entre organizaciones e instituciones, las primeras deben funcionar dentro del marco impuesto por las instituciones, es así que, al tratarse de problemas estructurales derivados de la actividad económica, las soluciones para las plazas de mercado del barrio Bolívar y La Esmeralda las deben proveer las instituciones.

De otro lado, también resulta pertinente indagar sobre las condiciones en las que se lleva a cabo el trabajo en el contexto de las galerías. Como lo manifiesta Touraine (1998), cuando se alude a la calidad del trabajo se alude a tres aspectos: regularidad, protección y autonomía. De igual manera, la Organización Internacional del Trabajo (OIT, 2003, p. 23) define un empleo formal de calidad como "aquel que es seguro, estable, libre de riesgo para la salud física y mental en que se desempeña el trabajador, realizado bajo condiciones de dignidad y respeto a la seguridad y leyes sociales del trabajo".

Los empleos que no cumplen con las características mencionadas o que lo hacen únicamente en forma parcial se consideran informales. Hay varios tipos de empleos informales, entre ellos destaca el empleo infantil, pues este es común y tiene gran 
impacto en las plazas de mercado. El empleo infantil se puede definir como el trabajo de personas que no han cumplido con la edad mínima de escolaridad estipulada por el Ministerio del Trabajo del país, la cual es de quince años; a partir de esta edad y hasta los dieciocho años se puede emplear a una persona únicamente si se cuenta con autorización de los padres.

En común acuerdo con Pico y Salazar (2008), resulta válido contemplar las razones por las cuales los menores de quince años se emplean e incurren en trabajo infantil; es posible identificar tres razones en esencia: el trabajo como medio de subsistencia familiar; como medio de compra de bienes deseados; y como medio de formación en valores.

Sumado a lo anterior, en las plazas de mercado se identifican dinámicas económicas campesinas o populares caracterizadas por ser de producción familiar, la cual puede ser de carácter agrícola, pecuaria, forestal, pesquera o comercial. En este caso las unidades de producción son al mismo tiempo unidades de consumo y se diferencian de las empresas agropecuarias en cuanto las decisiones de producción y consumo están mediadas por el sistema de decisiones de la familia, que a su vez está determinado por procesos de economías comunales y características culturales propias.

Las personas establecen lazos de colaboración, cooperación en el trabajo y responsabilidad solidaria, y adoptan una participación activa de naturaleza democrática. Combinan sus actividades económicas con otras de tipo social, educativa, de desarrollo personal y grupal que los distingue de las organizaciones predominantes en el capitalismo individual, con la pretensión de aportar a un cambio social en pos de una sociedad mejor o más justa. Así, en palabras de Razeto (1993, p. 34), las economías populares son "organizaciones que buscan superar la marginación y el aislamiento, conectándose entre ellas de manera horizontal, formando coordinaciones y redes que les permitan proponerse objetivos de mayor envergadura".

A pesar de estas características, no se debe confundir la economía con la economía informal. Como lo manifiesta Ortiz (2002, p. 4):

La economía popular hace referencia a una realidad existente basada en el trabajo de hombres y mujeres de la ciudad y el campo que, desde sus situaciones de pobreza, exclusión, desempleo y subempleo ponen en marcha actividades económicas que tienen como finalidad satisfacer sus necesidades básicas. En el segundo caso, el concepto "informal" estricto sensu hace referencia a algo que "no tiene forma" o bien parte de la negación de algo (prefijo "in"); no parte de la afirmación de la existencia de una realidad clara y distinguible que funciona en base a una racionalidad. La "economía informal" se refiere a actividades que no se encuadran en un marco jurídico o legal 
Variables asociadas al comportamiento de los ingresos por ventas en las principales plazas de mercado de Popayán, Colombia

(se les llama actividades ilegales) al punto que la gran alternativa que se propone es "cambiar el marco legal" para permitir el desarrollo del sector informal, como si el problema se solucionara únicamente modificando "formalmente" la normatividad sin producir cambios en la economía real, por ejemplo, en la distribución.

Otros autores aceptan algún grado de informalidad, pero no es lo común, por ejemplo Coraggio (Redacción Bogotá, 2013, p. 5) manifiesta que:

Una parte de los emprendimientos de la economía popular son informales. Es decir que no tienen un registro, personería jurídica, ni pagan impuestos. Pero no toda la economía popular es informal. Muchos de los pequeños comercios que vemos están registrados y eso es economía popular, como los artesanos, por ejemplo. Entonces la informalidad no es la característica principal.

En este sentido, Coraggio (Redacción Bogotá, 2013) considera que el conjunto de trámites para convertir un negocio o apuesta productiva en legal son amplios, exigentes y los márgenes de ganancia se afectan por el pago de impuestos. Así las cosas, en su concepto, deben cambiar la legislación para que se flexibilicen los requisitos y este se pueda ver cobijado por los beneficios de la legalidad.

Lo anterior podría a su vez ayudar a resolver el problema de medición del impacto económico y social que presenta la economía popular, pues muchas veces este tipo de actividades no pueden ser registradas en censos o encuestas por su carácter intrínseco. Lo anterior plantea el interrogante sobre qué tan fiables son las cifras del nivel de actividad económica de un país o región, sobre todo en casos de economías emergentes en los cuales la economía popular y solidaria tiene cada vez mayor incidencia y participación en la sociedad y en la economía.

Los estudios sobre informalidad en plazas de mercado en Colombia y el exterior son muy escasos, los pocos que existen implementan análisis socioeconómicos descriptivos. Para la ciudad de Popayán, el único estudio publicado en esta línea (Hurtado, 2013), tuvo como objetivo indagar sobe las características socioeconómicas de la economía popular de la galería del barrio La Esmeralda. A través de un censo, Hurtado (2013) encontró, entre un gran conjunto de hallazgos, que en dicha plaza de mercado y sus alrededores, la actividad económica popular la desarrollan principalmente las mujeres (60\%). Con respecto al nivel educativo, tan solo $36 \%$ de los vendedores ha cursado algún grado de educación secundaria, lo que les ha conllevado un relativo fracaso al momento de buscar un empleo formal, ya sea en el sector público o en el privado. La plaza de mercado es un foco de recepción de migrantes del sector rural (50\%), atraídos por factores económicos como la búsqueda de empleo y la expectativa de mejores condiciones de vida (salud, educación o puestos de trabajo). 
El estudio de Perea (2012) concuerda con el de Hurtado (2013) al insinuar que las migraciones del campo a las ciudades han influido en gran medida en el incremento del desempleo, lo que a su vez dispara el comercio informal de las plazas de mercado, lo que genera diferentes problemas ambientales y de invasión del espacio púbico. Otro factor importante para tener en cuenta y que impacta el desarrollo de las plazas de mercado son los bajos niveles de ingreso de los participantes del sector informal, según Bayón, Roberts y Saraví (1998). De acuerdo con Ortiz, Uribe y García (2007), el promedio de los trabajadores formales gana más que los informales, lo que se podría corroborar al analizar las condiciones socioeconómicas de los trabajadores de las plazas de mercado. Las brechas de ingresos formal e informal y de no subempleo y subempleo son muy similares.

La informalidad en las plazas de mercado también muestra otras facetas. Gutiérrez y Restrepo (2002) se enfocan en el problema que acarrea en la población infantil y juvenil en la ciudad de Medellín. Se trata de un estudio de carácter descriptivo que recoge una muestra representativa, entre niños y adolescentes, que trabajan en varias plazas de mercado de esa ciudad. El objetivo es reconocer las condiciones, no solo sociales y económicas de dicha población, sino también aspectos laborales, psicosociales y nutricionales. Para ello, Los autores implementaron un muestreo aleatorio estratificado que arrojó 250 individuos encuestados. Los resultados, entre muchos otros, evidenciaron que el $82,8 \%$ de la muestra eran hombres con una edad promedio de 14,3 años (la edad de las mujeres era en promedio de 12,6). La mitad de ellos no estudiaba y quienes lo hacían apenas estaban cursando primaria. La jornada laboral de las mujeres fue de 46,7 horas semanales y para hombres de 46,0. Los hombres tenían un ingreso mensual que supera en el doble al de las mujeres. Sin importar el género, presentaban desnutrición y altas cargas físicas y psicosociales, lo cual les permite concluir a los autores que no es válido el argumento de que los trabajos en las plazas de mercado son aptos para los niños o jóvenes (Gutiérrez y Restrepo, 2002).

Existen otros estudios en Colombia que abordan la informalidad laboral, pero no desde la óptica de las plazas de mercado sino a nivel general en las principales ciudades del país. García $(2005 ; 2008)$ considera que la informalidad, si bien es un fenómeno que afecta a la nación de forma generalizada, depende de la dimensión local, es decir que es el reflejo de las características económicas y sociales propias de cada región. A través de un análisis con datos panel estimados bajo efectos fijos, García determinó que la estructura productiva industrial y la cercanía con otros centros urbanos afectan la informalidad laboral. La abundancia de mano no calificada y mercados que absorben pocos trabajadores redireccionan demandas de trabajo hacia actividades mal remuneradas e inestables, sobre todo en ciudades 
Variables asociadas al comportamiento de los ingresos por ventas en las principales plazas de mercado de Popayán, Colombia

o regiones con mercados internos pequeños, ubicación periférica y abundancia en actividades agrícolas. Esto conforma una estructura económica segmentada por regiones bajo la cual las condiciones laborales desmejoran en la medida en que la economía local tiene menor capacidad para absorber fuerza de trabajo.

Finalmente, en una línea más centrada en el mercado laboral en sí, López (2010) buscó esquematizar las principales tendencias del mercado laboral colombiano en las siete ciudades principales del país y proponer medidas de política económica. Mediante una revisión exhaustiva de datos laborales, el autor estableció que el empleo formal en Colombia va de la mano con el nivel de educación, por tanto, las personas menos educadas no tienen otra alternativa que ingresar a empleos informales. Para menguar el problema, se indica que no basta únicamente con mejorar el crecimiento económico, sino que deben entrar a actuar otras estrategias que van desde la supresión de la negociación del salario mínimo y su estabilización en términos reales, pasan por la educación gratuita para poblaciones vulnerables, una reforma en salud y pensión para asegurar el cubrimiento a los trabajadores informales que ganan menos de un salario mínimo, hasta la consolidación de un seguro de desempleo.

En el ámbito internacional se pueden encontrar múltiples estudios sobre las plazas de mercado, pero desde ópticas muy diferentes. Existen algunos trabajos sobre América Latina, como los compilados por Cheng y Lacroix (2014), en los cuales se estudian las plazas de mercado de países como Colombia, Perú, Bolivia y Ecuador. Estos estudios abordan reflexiones y conocimientos relativos a las condiciones de acceso al mercado de las familias campesinas andinas, así como elementos sobre soberanía alimentaria. Otras investigaciones abordan la dinámica de los mercados informales y las plazas de mercado en su relación con las ciudades, sus formas de apropiación y transformación del espacio urbano y con la conservación del patrimonio cultural. Tal es el caso del estudio de Duclos (2017) sobre los mercados de pulgas en la ciudad de París, así como el de Rocha, Fridman y Ríos (2012) sobre el mercado móvil del municipio de Suina en Nicaragua. Otros se enfocan en el trabajo, como el de Rojas et al. (2010), cuyo objetivo era determinar condiciones de vida, prácticas de trabajo, efectos en la salud y factores de riesgo asociados para un grupo de menores que laboraban en un mercado público en Valencia, Venezuela.

Como se puede observar, el empleo informal es un tema tangencial para diferentes estudios emprendidos sobre las plazas de mercado. Este estudio intenta avanzar un poco más al tomar en consideración tanto un análisis descriptivo como uno estocástico que permita develar los aspectos relacionados con los ingresos monetarios de los trabajadores, formales e informales. 


\section{ASPECTOS SOCIOECONÓMICOS DE LOS COMERCIANTES DE LAS PLAZAS DE MERCADO DE LOS BARRIOS BOLIVIVAR Y LA ESMERALDA DE LA CIUDAD DE POPAYÁN}

En las plazas de mercado de la ciudad se presenta gran variedad de problemáticas en aspectos económicos, sociales, culturales, administrativos y ambientales atribuidos a una insuficiente intervención política y social. Pese a ello, también existen potencialidades que vale la pena mencionar, una de ellas es que las plazas de mercado son articuladoras de diferentes comunidades, costumbres y tradiciones, además de ser un escenario en el cual suceden importantes relaciones comerciales en las cuales confluyen flujos significativos de productos y personas.

Las galerías representan el espacio en el cual la ciudad y los municipios cercanos se abastecen de alimentos y productos de primera necesidad. Situaciones como los problemas de movilidad por la expansión del comercio informal, la contaminación ambiental y la seguridad deterioran el estado, imagen y confianza en las plazas de mercado y lugares aledaños. En este sentido, la ocupación indebida del espacio público es también un reflejo de una crisis social urbana. La administración municipal de la ciudad de Popayán, interesada en propiciar una transformación urbanística de la ciudad, enfrenta la problemática necesidad de modernizar sus galerías, razón por la cual solicitó al Ormet en el 2015, un estudio socio económico que permitiera caracterizar los comerciantes de la galería del Barrio Bolívar y al año siguiente, 2016, solicitó el mismo estudio para la plaza de mercado del barrio La Esmeralda. La información aquí contenida resulta de estas dos investigaciones que fueron unos de los insumos que dos administraciones municipales usaron para el diseño de la política pública en la ciudad de Popayán.

Los resultados de la presente investigación se basan en información primaria levantada a partir de un censo en cada galería. se obtuvo un total de 1.286 observaciones válidas para el barrio Bolívar y 960 para La Esmeralda. Las encuestas estuvieron dirigidas a los encargados de cada unidad económica (dueño o administrador) y se indagó sobre aspectos sociodemográficos de los comerciantes, así como de aspectos comerciales y legales de las unidades económicas. Los mapas de la página siguiente muestran el área correspondiente al levantamiento de la información en cada plaza de mercado.

A pesar de evidenciar procesos y problemáticas similares, se pudo detectar una gran diferencia en la dinámica de ambas galerías: mientras que en el barrio Bolívar buena parte de los negocios se localizan por fuera del edificio destinado para tal fin y el espacio público aledaño presenta mayor ocupación, en la galería La Esmeralda la mayoría de los negocios están localizados al interior del edificio y la ocupación del espacio público en sus inmediaciones es menor. Cabe resaltar que la información recolectada a través del instrumento se nutrió de talleres cualitativos realizados con 
actores claves de ambas plazas de mercado, lo que permitió construir el perfil de los comerciantes y de los negocios de ambos sectores. A continuación, se analizan los principales hallazgos.

Figura 1. Mapa de georeferenciación del levantamiento de la información

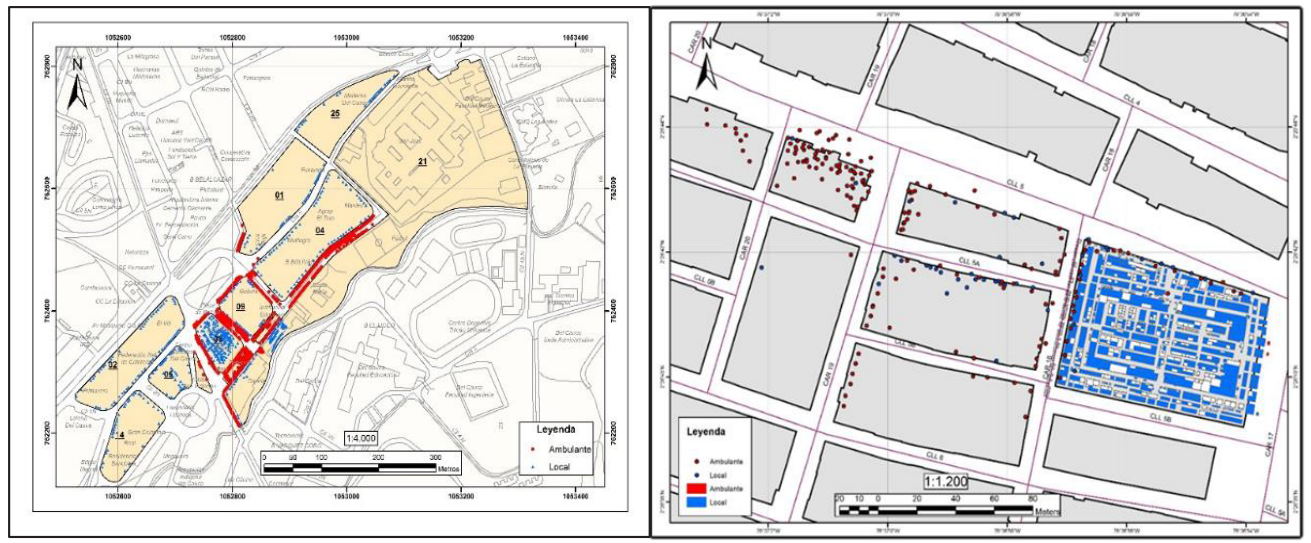

Fuente: elaborado por el Centro de Estudios Urbanos con datos de las encuestas

El censo realizado en las zonas de estudio permitió identificar que la dinámica económica de las plazas de mercado está soportada por dos tipos diferentes de negocios, uno de ellos que se podría llamar mayorista y cuyo volumen de ventas está muy por encima de los llamados minoristas, que son la gran mayoría de las unidades económicas encontradas en ambas galerías.

Ambas investigaciones mostraron un perfil del negociante promedio del sector que evidencia la participación de la mujer, alrededor del $59 \%$ de los puestos de trabajo son atendidos por mujeres en la galería del Barrio Bolívar y 67\% en el caso de la galería La Esmeralda, el $41 \%$ y el 33\% son atendidos por hombres respectivamente.

Figura 2. Gráfica sobre el sexo de los comerciantes

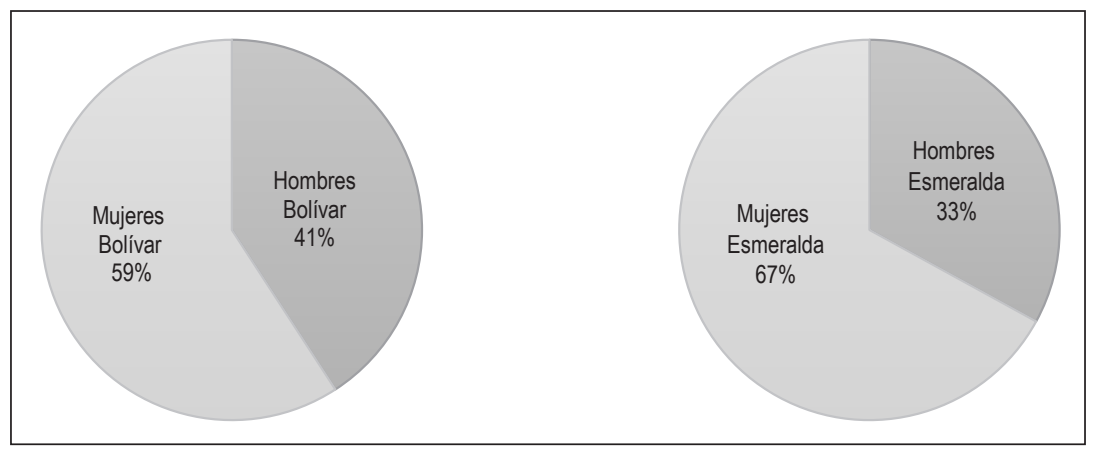

Fuente: elaboración propia con base en datos de los estudios socioeconómicos de ambas galerías 
Esta participación activa y mayoritaria de la mujer como proveedora de ingresos para su hogar es cada vez mayor, y puede tener varias explicaciones, por un lado, el logro de ciertas vindicaciones, sin desconocer también factores externos que muchas veces las llevan a asumir por completo la responsabilidad económica de su hogar, además de su tradicional rol en el cuidado y reproducción del mismo.

\section{Figura 3. Pirámide poblacional (quinquenal)}

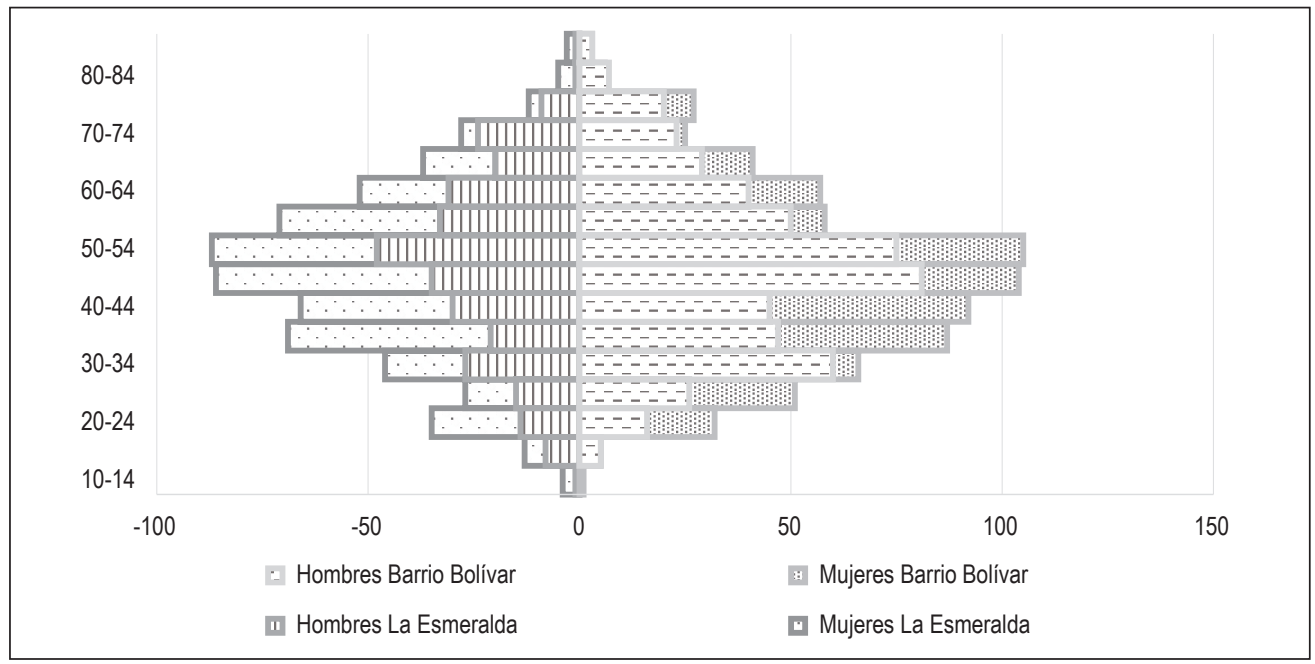

Fuente: elaboración propia

En las galerías estudiadas hay un predominio de población en edad adulta dado que una parte representativa de la población censada se encuentra en el rango de edad comprendido entre los 45 y 55 años, 47 años es la edad promedio de los comerciantes. Esta pirámide es de tipo regresiva, ya que es más ancha en los grupos superiores que en la base, probablemente debido a la aparente inexistencia de trabajo infantil en la zona objeto de estudio, también al envejecimiento continuo de las personas dedicadas a alguna actividad en la plaza de mercado, e incluso podría recoger el impacto del fenómeno del desplazamiento con la presencia de población migrante y actualmente asentada en la ciudad de Popayán, esto tomando en consideración que alrededor del $85 \%$ de los encuestados se ubican en un rango de edad productiva laboralmente.

El grado de escolaridad más alto alcanzado por los comerciantes -en promedio- es la básica primaria. En ambas galerías, este nivel de educación tiene una participación del $47 \%$, la culminación de secundaría representa el nivel de escolaridad del 33\% de los comerciantes del barrio Bolívar y del 35\% de los comerciantes de la galería La Esmeralda. Esto explicaría los bajos niveles de ingresos registrados por la 
mayoría de comerciantes, puesto que, por diferentes motivos económicos, culturales o físicos, dicha población ha interrumpido su proceso de formación educativa a temprana edad. Estas personas tuvieron que ingresar al mercado laboral (informal o no) con el fin de alcanzar la subsistencia personal y/o familiar, lo cual los ha limitado a ocuparse en determinadas actividades que, en otra situación pudiesen significar un mayor nivel de ingresos.

Figura 4. Nivel educativo

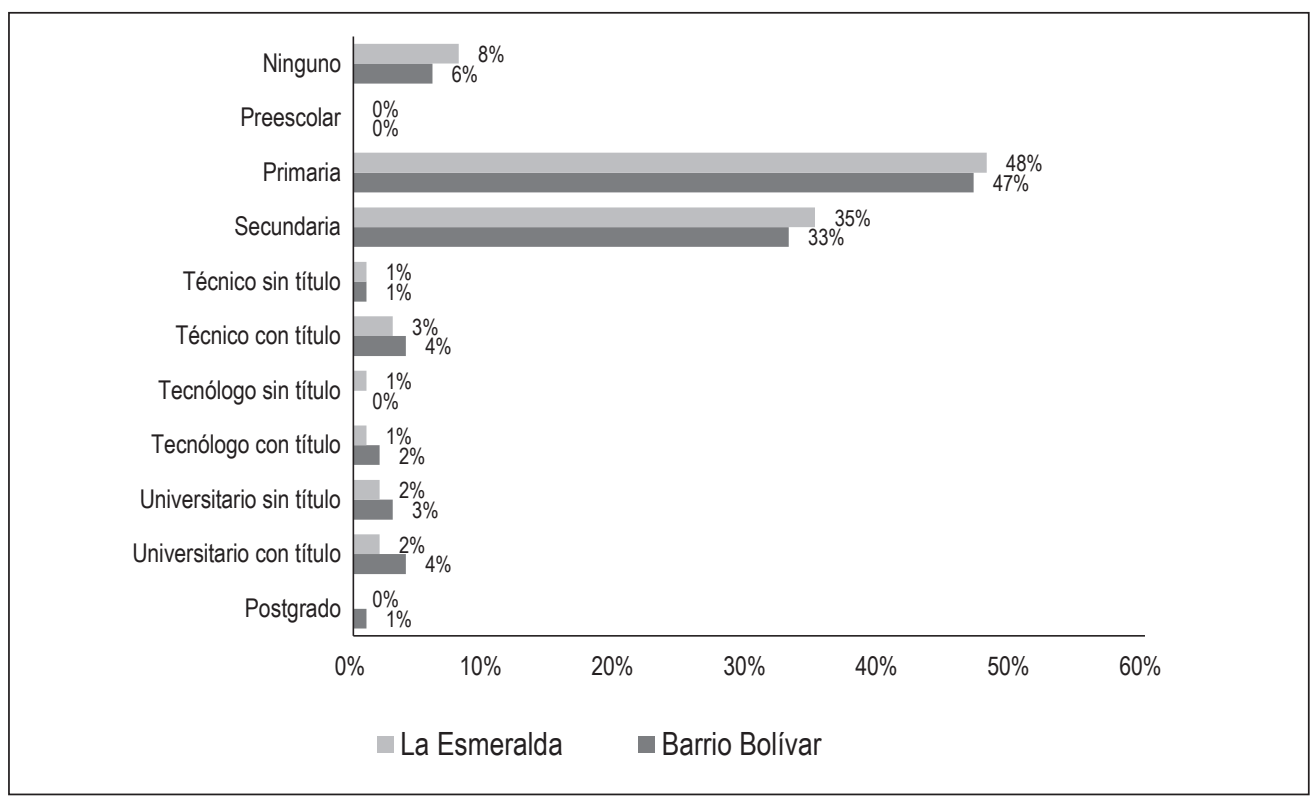

Fuente: elaboración propia

Los negocios predominantes en las galerías son pequeñas unidades económicas en las que el dueño es el mismo trabajador, las dotaciones de capital son bajas y las garantías en seguridad social dependen fundamentalmente del régimen subsidiado. En la galería La Esmeralda el 97\% de los comerciantes se consideran minoristas y el $3 \%$ de ellos mayoristas, a diferencia del Barrio Bolívar en el cual el 90\% se reconocen como minoristas y el 10\% como mayoristas. Esto tiene sentido toda vez que es la galería del barrio Bolívar la que concentra la llegada de todos los alimentos y de allí se distribuyen al resto de la ciudad y de las demás galerías.

Existe una fuerte relación entre los pequeños negocios que se proveen en la misma plaza de mercado y revenden sus productos con un pequeño margen de ganancia debido a la falta de capital de trabajo. El acceso a los canales formales de 
crédito es muy limitado para los negocios de las plazas de mercado, esto se suma a la dependencia de los mayoristas como factores que incrementan el riesgo de pérdida de las unidades económicas más pequeñas.

Figura 5. Número de establecimiento por actividades económicas

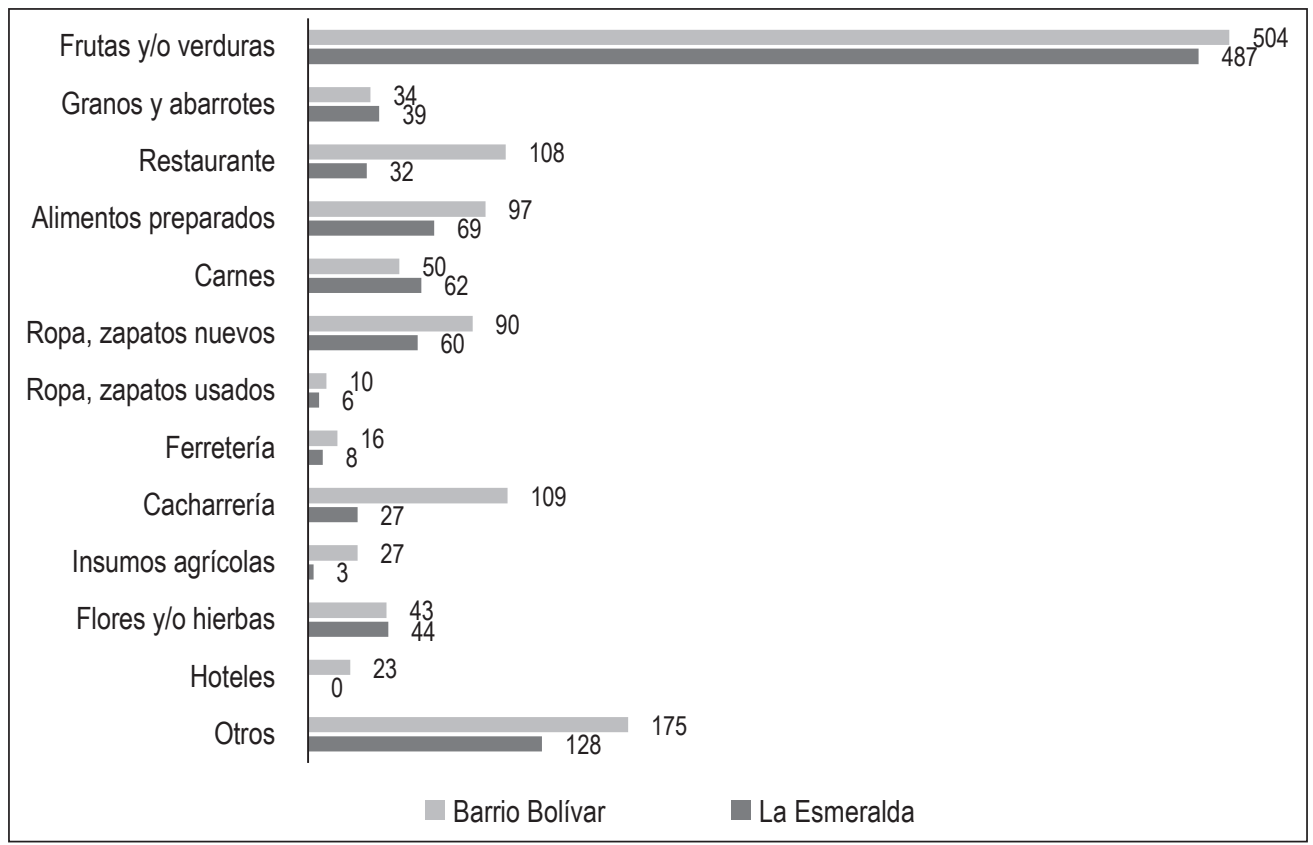

Fuente: elaboración propia

La principal actividad económica de las galerías es la comercialización de frutas y verduras que corresponde a 487 negocios en La Esmeralda y 504 en el barrio Bolívar. La galería es el espacio en el cual los pequeños productores venden el producto de sus parcelas, estas son pequeñas economías de subsistencia y las familias que derivan su sustento de dicha actividad encuentran en las plazas de mercado el lugar donde pueden vender sus productos y a su vez, abastecerse de múltiples bienes y servicios que permitan satisfacer sus necesidades más básicas.

La llegada de población campesina e indígena, y todas las relaciones sociales y culturales que derivan de la venta de sus productos algunos días en la plaza de mercado, es lo que popularmente se denomina mercado campesino que se desarrolla principalmente, los viernes en el barrio Bolívar y los sábados en La Esmeralda. Este es un término acuñado en la galería que encierra toda la dinámica económica generada en estos días por la afluencia masiva de vendedores, principalmente de productos agrícolas. Es así como muchas personas de la comunidad reconocen que 
Variables asociadas al comportamiento de los ingresos por ventas en las principales plazas de mercado de Popayán, Colombia

su actividad económica depende fundamentalmente de este movimiento comercial y cultural. Adicionalmente, alrededor de la venta de alimentos funcionan otros negocios que fungen como sitios de abastecimiento para los comerciantes que llegan de los demás municipios del Cauca.

Las unidades económicas predominantes en las galerías estudiadas son pequeños negocios, en su mayoría informales, con una alta dependencia de canales informales e ilegales de crédito y con muy pocas posibilidades de generar empleos de calidad. Es así como esta dinámica informal asociada a las plazas de mercado ha conllevado al deterioro del espacio público por cómo se vienen desarrollando, especialmente en medio de la ocupación por vendedores informales atribuida a la falta de espacio disponible al interior de las plazas, por el manejo y disposición final de los residuos sólidos y la contaminación auditiva.

\section{ANÁLISIS ESTADÍSTICO}

\subsection{Modelo de regresión cuantílica}

Siguiendo a Vicèns y Sánchez (2012), a diferencia del modelo de mínimos cuadrados ordinarios (MCO) -cuyo objetivo es estimar la esperanza condicional de la variable endógena para valores dados de las variables exógenas-, la regresión cuantílica busca estimar los cuantiles condicionales de la variable endógena. Esto obedece a que la heterogeneidad de los datos (heterocedasticidad), la presencia de datos atípicos (outliers), o los cambios estructurales impiden que la estimación por MCO sea la más robusta. Por tanto, la regresión por cuantiles supera este inconveniente y crea distintas líneas de regresión para los diferentes cuantiles, de la siguiente forma:

$$
y_{i}=X_{i} \beta_{\delta}+\varepsilon_{i \delta}
$$

Donde $y_{i}$ es la variable explicada; $X_{i}$ es la matriz de variables explicativas; $\beta_{\delta}$ es el parámetro que se desea estimar para el cuantil $\delta$; y $\varepsilon_{i \delta}$ son los errores aleatorios también correspondientes al cuantil bajo análisis. En este sentido, para obtener los parámetros este método minimiza las desviaciones absolutas (no las desviaciones cuadradas como en $\mathrm{MCO}$ ) castigando los outliers de forma lineal y restándole trascendencia a su presencia, a diferencia del MCO. La minimización de los errores absolutos viene dada por la siguiente expresión:

$$
\min _{\beta_{\delta} \in \mathbb{R}}\left[\sum_{Y_{i} \geq X_{i} \beta_{\delta}} \delta\left|y_{i}-X_{i} \beta_{\delta}\right|+\sum_{Y_{i}<X_{i} \beta_{\delta}}(1-\delta)\left|y_{i}-X_{i} \beta_{\delta}\right|\right]
$$


Donde $\delta$ es el cuantil analizado; $y_{i}$ son las observaciones de la variable endógena; y $\mathrm{X}_{i} \beta_{\delta}$ es el valor que minimiza la expresión. Este último valor deja una proporción $\delta$ de datos por debajo y $(1-\delta)$ por encima, siendo $\delta$ un valor entre 0 y 1 que es igual al cuantil que se desea hallar. Ya que no se hacen supuestos iniciales sobre la distribución de los errores, con la ayuda del método generalizado de momentos se llega a concluir que el parámetro estimado se distribuye asintóticamente normal:

$$
\sqrt{n}\left(\hat{\beta}_{\delta}-\beta_{\delta}\right) \stackrel{\mathrm{L}}{\rightarrow} \mathrm{N}\left(0, \Pi_{\delta}\right)
$$

Donde $\Pi_{\delta}$ es la matriz Var-Cov de estimadores que viene dada por:

$$
\Pi_{\delta}=\delta(1-\delta)\left(\mathrm{E}\left[f_{\varepsilon \delta}\left(0 \mid x_{i}\right) x_{i} x_{i}^{\prime}\right]\right)^{-1} \mathrm{E}\left[x_{i} x_{i}^{\prime}\right]\left(\mathrm{E}\left[f_{\varepsilon \delta}\left(0 \mid x_{i}\right) x_{i} x_{i}^{\prime}\right]\right)
$$

Donde

$f_{\varepsilon \delta}\left(0 \mid x_{i}\right)$ es la matriz de densidad de $\varepsilon_{i \delta}$. Con las ecuaciones se hizo la inferencia estadistica de los parámetros estimados, finalmente, la medida de bondad de ajuste viene dada por:

$$
\text { Pseudo R } R^{2}=1-\left[\frac{\sum_{i=1}^{n}\left|y_{i}-\hat{y}_{i}\right|}{\sum_{i=1}^{n}\left|y_{i}-y_{\delta}\right|}\right]
$$

Donde el numerador es la sumatoria de los residuales en valor absoluto y el denominador es la sumatoria de las desviaciones de la observación frente al cuantil $\delta$.

\subsection{Modelo estocástico}

El objetivo del modelo es identificar y cuantificar las variables asociadas al cambio relativo en los ingresos por ventas mensuales de los negocios formales e informales, ubicados tanto en la galería Bolívar como en la galería La Esmeralda, con el fin de conocer más de cerca la problemática económica y social por la que atraviesan sus propietarios y poder realizar análisis comparativos entre ellas.

Siguiendo a Gómez, Fajardo y Cadena (2018), debido a la inexistencia de un modelo previo o teoría sobre los determinantes del ingreso por ventas, se escogen las variables explicativas con mayor correlación con la variable endógena y se añaden aquellas que se cree que explican de alguna manera el comportamiento del ingreso por ventas (las hipótesis se encuentran más adelante) $)^{2}$. De acuerdo a Wooldridge (2010, p. 3), los modelos econométricos se basan en teorías, pero también se pueden

Las tablas de correlación simple para ambas galerías se muestran en el anexo 1A y 1B. La significancia estadística de las correlaciones simples se evalúa por el siguiente estadístico de prueba: 
construir a través de la percepción o intuición, lo que presupone la no existencia de una teoría previa: "Algunas veces, el modelado económico formal es el punto de partida del análisis empírico, pero es más común el empleo de teorías económicas menos formales o incluso apoyarse por completo en la intuición". Si bien el modelo que se presenta es ateórico, no debe ser espurio ya que las variables incluidas provienen de los aspectos sociales, económicos e institucionales que rodean a los establecimientos y sus propietarios, manifestados por los mismos actores en las galerías analizadas.

En este orden de consideraciones se implementa un modelo estocástico de regresión cuantílica del tipo log-lin. La razón de utilizar modelos log-lin es que permiten conocer las tasas de crecimiento del ingreso por ventas dado un conjunto de características de la población y de los establecimientos comerciales. De otro lado, la regresión cuantílica se justifica no solo porque los datos provienen de una encuesta con una gran cantidad de observaciones, sino por el elevado grado de dispersión de los ingresos totales por ventas. El interés de enfocarse en los determinantes de los ingresos por ventas en las colas y otras partes no centrales de la distribución condicional requiere de regresiones por cuantiles (Tokdar y Kadane, 2012). Dada la alta varianza, los cuantiles elegidos son 25, 50 y 75, más los cuantiles de las colas (10 y 90) de acuerdo con Julio, Rodríguez y Zárate (2005).

$$
t^{*}=\frac{\rho\left(c_{i}, c_{j}\right) \sqrt{\mathrm{N}-2}}{\sqrt{1-\left(\rho\left(c_{i}, c_{j}\right)\right)^{2}}}
$$

Donde $t^{*}$ es el estadístico de prueba $\left(t_{c}\right) ; \rho\left(c_{i}, c_{j}\right)$ representa el coeficiente de correlación lineal entre las variables $i$, j; y $\mathrm{N}$ es el número de datos de la muestra. Como en este caso $\mathrm{N}_{\mathrm{B}}=1,131$ para la galería Bolívar y $\mathrm{N}_{\mathrm{E}}=882$ para la Esmeralda, y asumiendo un nivel de significancia del $5 \%$, se implementa la regla "2- $t$ ". Por tanto, cuando $t^{*}=2$, la correlación $\rho\left(c_{i}, c_{j}\right)$ es estadísticamente significativa si su valor absoluto es igual o mayor que 0,056 para la galería Bolívar y 0,067 para La Esmeralda, de acuerdo con la formula anterior.

Para la galería Bolívar la correlación entre la variable dependiente y las explicativas, supera estos valores con creces, a excepción de tres variables que recogen si el dueño de un negocio posee otro en la misma galería, el tamaño o área del negocio y si recibe apoyo institucional. Por tanto, la primera se elimina, pero las demás se mantienen debido a la diferenciación de tamaños entre negocios mayoristas y minoristas requerida en el estudio y si la alcaldía municipal les presta ayuda institucional periódica.

En el caso de la galería Esmeralda, sucede exactamente lo mismo con las mismas variables, excepto con aquella que recoge la pertenencia a una organización social por parte del vendedor, la cual no guarda una relación muy estrecha con el nivel de ingresos, pero se mantiene debido a que la participación en organizaciones sociales en Popayán y el Cauca es un fenómeno arraigado en la historia de la región, a tal punto que es el departamento con el mayor número de líderes sociales asesinados en lo corrido del 2018.

En cuanto a la multicolinealidad, si bien los valores de las correlaciones sobrepasan el valor critico hallado con la formula anterior, las relaciones lineales no son muy elevadas, sobre todo para la galería la Esmeralda. Así se sospecha de una presencia muy baja de este problema. Más adelante en el anexo 2 se muestra una prueba más formal para evaluar el impacto del fenómeno. 
La utilización de un método tradicional como mínimos cuadrados ordinarios (MCO) con una variable tan dispersa sesgaría los resultados debido a la fuerte presencia de heterocedasticidad. La tabla 1 muestra la prueba para detección de heterocedasticidad y evidencia que para en galerías existe un elevado nivel de dispersión en los ingresos por ventas que se acentúa más en la galería Bolívar, ya que el estadístico de prueba es mayor frente al de La Esmeralda. Este resultado justifica la regresión por cuantiles.

Tabla 1. Prueba de heterocedasticidad Breusch-Pagan/Cook-Weisberg

\begin{tabular}{|l|c|c|}
\cline { 2 - 3 } \multicolumn{1}{c|}{} & Bolivar & La Esmeralda \\
\hline chi2(15) & 64,64 & 31,03 \\
\hline Prob>chi2 & 0,000 & 0,0087 \\
\hline
\end{tabular}

Fuente: elaboración propia con datos de la Alcaldía Municipal de Popayán

El gráfico de la figura 6 muestra la función de distribución acumulada (FDA) observada del logaritmo de los ingresos por ventas, la cual señala que para ambas galerías los cuantiles 10, 25, 50, 75 y 90 son aproximadamente iguales a 12, 13, 14, 15 y 16 en la escala logarítmica. Se nota que los ingresos son similares para el cuantil 10, mientras que a partir del cuantil 15 se empiezan a distanciar cada vez más hasta el último cuantil, en el que esto es más pronunciado.

Figura 6. FDA empírica del logaritmo del ingreso por ventas de las galerías La Esmeralda y Bolívar por cuantiles

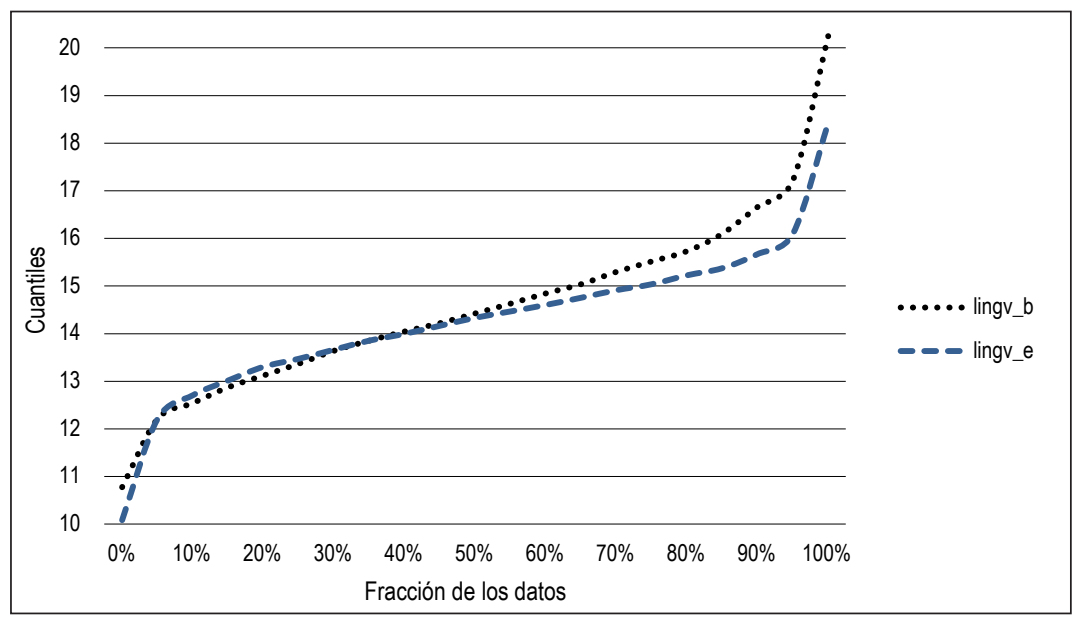

Fuente: elaboración propia con datos de la Alcaldía Municipal de Popayán

Donde: lingv _ b es logaritmo del ingreso por ventas de la galería Bolívar; y ling _ e es logaritmo del ingreso por ventas de la galería La Esmeralda. 
Variables asociadas al comportamiento de los ingresos por ventas en las principales plazas de mercado de Popayán, Colombia

Esto sugiere que los ingresos por ventas de los negocios más pequeños son muy similares en ambas galerías para la cola izquierda, pero son disimiles para los más grandes en la cola derecha. En efecto, la galería Bolívar, a diferencia de la Esmeralda, cuenta con depósitos de diferentes tipos (tubérculos, frutas, verduras) que surten a almacenes de cadena, supermercados ancla, supermercados y tiendas de barrio a nivel local, lo que amplía los montos de dinero que se mueven frente a la otra galería.

El modelo intenta mostrar aspectos de diversa índole que se relacionan con el comportamiento de los ingresos por ventas mensuales de los establecimientos. Está expresado en logaritmo natural debido a su elevada varianza y las variables explicativas en niveles, por lo que los coeficientes se deben entender como tasas de crecimiento del ingreso. Las variables exógenas se dividen en tres grupos:

a. El vector $\mathbf{X}$ recoge aspectos socioeconómicos de los propietarios: sexo, edad, lugar de residencia, nivel de escolaridad y si posee algún tipo de seguridad social como cesantías, pensión o riesgos laborales.

b. El vector $\mathbf{W}$ muestra las características del negocio: tipo de actividad económica, días a la semana que opera, si es mayorista o minorista, si lleva registros contables, la existencia de una sucursal en la galería, y por último el tamaño del establecimiento comercial medido por el área que ocupa.

c. El vector $\mathbf{Z}$ identifica aspectos de carácter institucional: apoyo con programas de asistencia o capacitación del Estado, pertenencia del propietario a organizaciones sociales, acceso al sistema financiero y subsidios otorgados por el Estado.

Así, la estructura del modelo es la siguiente:

$$
\begin{gathered}
\mathrm{Y}_{i \delta j}=\beta_{\delta j}+\sum_{k=1}^{5} \beta_{k \delta j} \mathrm{X}_{i}+\sum_{m=1}^{6} \delta_{m \delta j} \mathrm{~W}_{i}+\sum_{h=1}^{4} \gamma_{h \delta j} \mathrm{Z}_{i}+\varepsilon_{i \delta j} \\
i=1, \ldots, n \quad ; \quad \delta=0,1 ; 0,25 ; 0,5 ; 0,75 ; 0,90 ; \quad j=1,2
\end{gathered}
$$

Donde $Y_{i \delta j}$ muestra los ingresos del negocio $i$ en el cuantil $\delta$ para la galería $j$; $\beta_{k \delta j} ; \delta_{m \delta j} ; \gamma_{h \delta j}$ son los estimadores cuantílicos del establecimiento $i$ en el cuantil $\delta$ para la galería j; las características sociales, económicas e institucionales de los propietarios y los negocios se recogen con $\mathrm{X}_{i} ; \mathrm{W}_{i} ; \mathrm{Z}_{i}$, respectivamente. Los errores estocásticos del establecimiento i en el cuantil $<<$ seec _ A _ ${ }^{5}$ _ 28.wmf $>>$ para la galería j se recogen con el término $<<$ seec _ A _ ${ }^{2}$ 2 29.wmf $>>$ ae recordar que en las regresiones cuantílicas no se asume ningún tipo de distribución en ellos.

La tabla 2 recoge las variables explicativas consideradas en el modelo y las hipótesis de los signos esperados de los parámetros. 
Tabla 2. Variables exógenas del modelo

\begin{tabular}{|c|c|c|c|c|c|c|}
\hline Aspecto & Variable & Nombre & Tipo & Valor & Signo & Explicación \\
\hline \multirow{7}{*}{ 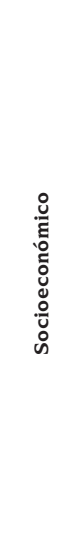 } & Género & sexo & Dicotómica & 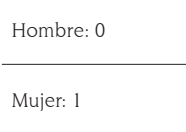 & $(-)$ & $\begin{array}{l}\text { Debido a la doble jornada laboral, los bajos niveles de cualificación } \\
\text { y en general la discriminación por género que enfrentan las } \\
\text { mujeres payanesas en el mercado laboral local, lo que incide } \\
\text { de forma negativa en los ingresos que generan las apuestas } \\
\text { productivas en las galerías. }\end{array}$ \\
\hline & Edad & edad & Cuantitativa & $>0$ & $(-)$ & $\begin{array}{l}\text { A mayor edad menos vitalidad, habilidad o destreza para manejar } \\
\text { un negocio que en gran parte se caracteriza por estar ubicado } \\
\text { a la intemperie, la necesidad de utilizar fuerza bruta, o largas } \\
\text { horas de trabajo. }\end{array}$ \\
\hline & \multirow{2}{*}{ Residencia } & \multirow{2}{*}{ reside } & \multirow{2}{*}{ Dicotómica } & Popayán:1 & \multirow{2}{*}{$(+)$} & \multirow{2}{*}{$\begin{array}{l}\text { Si reside en Popayán implicará menores costos en transporte } \\
\text { alimentación o la poswwibilidad de destinar más horas de trabajo } \\
\text { que aquellos que vienen de otras ciudades o municipios cercanos }\end{array}$} \\
\hline & & & & Otro:0 & & \\
\hline & Escolaridad & esc & Cuantitativa & $>0$ & $(+)$ & $\begin{array}{l}\text { Debe tener un impacto directo en las ventas del establecimiento } \\
\text { ya que las personas con mayores niveles de escolaridad tienden } \\
\text { a emprender negocios más grandes, formales, o con mayor } \\
\text { estabilidad de demanda. }\end{array}$ \\
\hline & \multirow{2}{*}{$\begin{array}{l}\text { Seguridad } \\
\text { Social }\end{array}$} & \multirow[b]{2}{*}{ ss } & \multirow{2}{*}{ Dicotómica } & Al menos una: 1 & \multirow{2}{*}{$(+)$} & \multirow{2}{*}{$\begin{array}{l}\text { Si los propietarios tienen algún tipo de seguridad social los } \\
\text { ingresos deben ser superiores a quienes no la posean, pues el } \\
\text { negocio tendrá algún grado de formalidad. }\end{array}$} \\
\hline & & & & Otro :0 & & \\
\hline \multirow{7}{*}{ 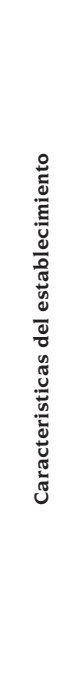 } & $\begin{array}{l}\text { Negocio } \\
\text { de frutas y } \\
\text { verduras }\end{array}$ & acteconeg & Dicotómica & $\begin{array}{l}\text { Frutas /verduras: } 1 \\
\text { Otro :0 }\end{array}$ & $(-)$ & $\begin{array}{l}\text { Las unidades productivas de este tipo si bien son característicos } \\
\text { en las plazas de mercado, la competencia es muy alta y el impacto } \\
\text { económico que genera es muy bajo frente a otras apuestas } \\
\text { productivas en las galerías. }\end{array}$ \\
\hline & $\begin{array}{l}\text { Días } \\
\text { apertura }\end{array}$ & diasem & Cuantitativa & $>0$ & $(+)$ & $\begin{array}{l}\text { Existen negocios que por diferentes motivos solo permanecen } \\
\text { abiertos al público algunos días a la semana, por lo que se infiere } \\
\text { que a mayores días de apertura más ventas generan. }\end{array}$ \\
\hline & Mayorista / & \multirow{2}{*}{ maymin } & \multirow{2}{*}{ Dicotómica } & Minorista:1 & \multirow{2}{*}{$(-)$} & \multirow{2}{*}{$\begin{array}{l}\text { Evidentemente la expectativa es que se presenten mayores } \\
\text { niveles de ingresos por volumen de ventas para los mayoristas } \\
\text { que para los minoristas. }\end{array}$} \\
\hline & Minorista & & & Mayorista:0 & & \\
\hline & $\begin{array}{l}\text { Registro } \\
\text { Contable }\end{array}$ & regcont & Dicotómica & $\begin{array}{l}\text { Registro: } 1 \\
\text { No registro: } 0\end{array}$ & $(+)$ & $\begin{array}{l}\text { Se espera una relación positiva con la variable endógena para la } \\
\text { categoría base, ya que es sintoma de formalidad. De otro lado, se } \\
\text { espera un signo negativo para los negocios informales. }\end{array}$ \\
\hline & $\begin{array}{l}\text { Otro } \\
\text { negocio }\end{array}$ & otroneg & Dicotómica & $\begin{array}{l}\text { Otro negocio: } 1 \\
\text { Solo uno: } 0\end{array}$ & $(+)$ & $\begin{array}{l}\text { Existen al interior de las galerías varios negocios del mismo propie- } \\
\text { tario, por tanto más sucursales generarán más ventas y viceversa. }\end{array}$ \\
\hline & Área & area & Cuantitativa & $>0$ & $(+)$ & $\begin{array}{l}\text { El tamaño del establecimiento no se pudo capturar con el número } \\
\text { de empleados por la presencia de valores perdidos. Por tanto, } \\
\text { se apeló a los metros cuadrados que el negocio ocupa. A mayor } \\
\text { tamaño o área se supone mayores ingresos por ventas. }\end{array}$ \\
\hline & Apoyo Ins- & & & No apoyo:1 & & El abandono estatal impide mejorar la calidad del establecimiento \\
\hline & titucional & apoyotnst & Dicutumined & Apoyo:0 & $(-1)$ & y afecta los ingresos de forma negativa. \\
\hline$\sqrt{7}$ & & & & Pertenece: 1 & & Pertenecer a cualquier organización fortalece el negocio ya que se \\
\hline 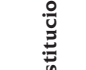 & Organización & org & Dicotómica & No pertenece:0 & $(+)$ & $\begin{array}{l}\text { en mayor permanencia en la galería, poder de negociación, entre } \\
\text { otros y por tanto mayores ingresos. }\end{array}$ \\
\hline$\Xi$ & & & & Formal: 1 & & Se espera que los ingresos disminuyan con los créditos gota a gota \\
\hline 这 & prestamos & prestamos & Dicotómica & Informal: 0 & $(+)$ & $\begin{array}{l}\text { y métodos extorsivos de cobro, por parte de algunos prestamistas } \\
\text { informales, generarían un detrimento en los ingresos. }\end{array}$ \\
\hline & & & & No rebibe: 1 & & La expectativa es que si tiene subsidio los ingresos serán más \\
\hline & Subsidios & subs & Dicotómica & Rebibe:0 & $(-)$ & $\begin{array}{l}\text { altos sobre todo en los negocios más pequeños que en los grandes } \\
\text { pues esto genera mayor estabilidad de la apuesta productiva. }\end{array}$ \\
\hline
\end{tabular}

\section{Fuente: elaboración propia}


Variables asociadas al comportamiento de los ingresos por ventas en las principales plazas de mercado de Popayán, Colombia

\section{RESULTADOS}

Las tablas 3 y 4 muestran que en general los 24 modelos estimados tienen un buen ajuste tanto en términos individuales como en conjunto 4 . Igualmente se evidencian diferencias marcadas entre los valores que asumen los parámetros cuantílicos, lo que confirma que la población analizada muestra un nivel de heterogeneidad alta 5 .

En el grupo de las variables socioeconómicas, específicamente en el género, bajo condiciones ceteris paribus, en los percentiles del 25 al 90 una propietaria mujer siempre obtiene menos ingresos por ventas que los propietarios hombres, así el negocio sea formal o informal o de la galería que se trate. Bajo MCO el resultado es similar, pero tiende a sobrevalorar los impactos en los cuantiles más bajos. Frente a la edad, su impacto -aunque mínimo- es estadísticamente significativo, sobre todo en los cuantiles más altos, lo que muestra que dejando todas las demás variables sin modificación, los ingresos por ventas decrecen en $1 \%$ por un año más de vida del propietario en la galería Bolívar y cerca del 2\% en La Esmeralda. El parámetro MCO oculta esta discrepancia ya que su valor es cercano al promedio $(1,5 \%)$ y no la destaca en los cuantiles 75 y 90.

En cuanto a la residencia, dejando todo lo demás constante, que el propietario resida en Popayán impulsa las ventas del negocio más que si no vive en esta ciudad, sobre todo en los cuantiles intermedios como el 25 y el 50 (mediana) en la galería Bolívar; en La Esmeralda este fenómeno se acentúa más en los cuantiles 75 y $90 .{ }^{6} \mathrm{El}$

3 Se incluye en las estimaciones los resultados del método MCO con el fin de compararlos con el modelo cuantílico.

4 Las pruebas de multicolinealidad, heterocedasticidad, variables omitidas y normalidad de este modelo se muestran para ambas galerías en el anexo 2. Los resultados revelan tanto para la galería Bolívar como para La Esmeralda que, en el caso de las relaciones lineales entre variables explicativas, el factor inflacionario de varianza (IVF) es cercano a uno para todas las variables y en promedio, por lo que se descarta la presencia de multicolinealidad. En el caso de la heterocedasticidad, el test de Breusch-Pagan/Cook-Weisberg de la galería Bolívar muestra homocedasticidad, pero en La Esmeralda el resultado es contrario; sin embargo, las estimaciones de los parámetros para ambas son consistentes ya que se obtienen bajo la rutina de Consistencia para heterocedasticidad y autocorrelación (HAC). La autocorrelación no se evalúa porque se tienen datos de corte transversal. El test de Shapiro-Wilk para la detección de normalidad en los errores muestra que se cumple en el caso de La Esmeralda, pero no en el de Bolívar, aunque aquí se apela al teorema del límite central para aproximarse a la normalidad, ya que se cuenta con más de 1.000 observaciones. Finalmente, la prueba de Ramsey para evaluar el sesgo por variable omitida presenta que no existe dicho problema en ambas galerías, lo que sugiere que el modelo está bien especificado.

5 En el caso de la regresión cuantílica, el parámetro estimado para una variable es la derivada del cuantil condicional del logaritmo del ingreso con respecto a cada variable explicativa. Por tanto, la diferencia con el modelo MCO es que el impacto se analiza en cuantiles específicos (Cade y Noon, 2003).

6 Debido a que la variable residencia es dicotómica (asume el valor de 1 si reside en Popayán y 0 en otro caso) y no se cuenta con los domicilios exactos de los vendedores, es imposible contrastar y corregir la existencia de autocorrelación espacial en los residuos de la regresión estimada por MCO. 
estimador por MCO muestra un sesgo alto porque sobrevalora su influencia, sobre todo en los negocios formales de la galería Bolívar, y la subvalora en La Esmeralda. De otro lado, los ingresos por ventas guardan una relación débil o poco relevante con los niveles de estudio alcanzados por los propietarios en las galerías, aunque sigue siendo relevante en cuantiles en los que se ubican las apuestas productivas informales de la Galería Bolívar, especialmente en el cuantil 25.

Con respecto a la seguridad social, bajo condiciones ceteris paribus, en general, sigue el mismo patrón para ambas plazas. Esta variable solo se relaciona positivamente en los ingresos por ventas tanto en los establecimientos formales como informales, pero solo para la mediana y los cuantiles más altos (75 y 90), exceptuando los negocios formales en La Esmeralda. Este resultado posiblemente corresponde a la relación estrecha entre personas que pertenecen a estratos económicos bajos y la exclusión de fondos de pensiones y cesantías. Vía MCO, los resultados solo son significativos para los negocios informales de la galería Bolívar.

En cuanto a las variables propias del establecimiento comercial, si la actividad económica del negocio pertenece a la venta y comercialización de frutas y hortalizas, considerando las restantes variables sin modificación, los niveles de ingresos por ventas son superiores frente a los que se dedican a otra actividad, sobre todo en los establecimientos informales del barrio Bolívar, en los cuales el impacto es incremental, sobre todo en los cuantiles mediano y medio alto (75), ya que las tasas de crecimiento inician en 36\% y finalizan en 47\%. En La Esmeralda, la situación es contraria (cuantiles 10 y 50) ya que, si bien la variable resulta ser significativa para los establecimientos informales, los signos son negativos, lo que evidencia que vender frutas y verduras en esta plaza reduce las ventas del establecimiento, ceteris paribus, resultado que se explica porque el volumen de ventas de estos establecimientos es menor en comparación con los del Bolívar, a pesar de representar el mayor número de negocios de este tipo. Los parámetros MCO subvaloran y sobrevaloran los impactos en los cuantiles más bajos para negocios informales y formales, respectivamente en la galería Bolívar.

Los días a la semana que funciona el establecimiento también tienen un comportamiento discrecional. En la plaza del barrio Bolívar los establecimientos informales reducen el ingreso si su establecimiento permanece abierto todos los días, mientras que en los formales se amplía en todos los cuantiles, con todo lo demás constante. En La Esmeralda la situación es contraria debido a que el tipo de negocio que más reporta ventas y permanece abierto durante todos los días de la semana es el dedicado a la comercialización de productos del hogar y vestido, por lo que permanecer abierto entre semana les garantiza mayores ingresos, situación 
Variables asociadas al comportamiento de los ingresos por ventas en las principales plazas de mercado de Popayán, Colombia

que se repite en los cuantiles 10 y 50 de los formales. De otro lado, en la galería La Esmeralda la estimación por MCO revela que se subvaloran las influencias de esta variable en los cuantiles por debajo de la mediana.

Frente a la distinción entre mayoristas y minoristas, bajo condiciones ceteris paribus, la variable resulta ser significativa para los negocios informales con impactos negativos cada vez más elevados entre los cuantiles (pasando de una tasa del 35\% al 90\%) y positivos para los formales en ambas plazas. Los negocios minoristas son en su mayoría informales, y por vía contraría es común que los formales sean mayoristas. Así, ser minorista reduce los ingresos por ventas de forma creciente en los negocios informales y en los formales tiende a elevarlos a través de los cuantiles. Bajo MCO se oculta esta situación toda vez que dicha distinción resulta ser no significativa para casi todos los escenarios analizados.

De otro lado, el registro contable muestra que dejando todo lo demás sin variación, los ingresos por ventas caen en todos los cuantiles analizados, tanto en establecimientos formales como informales para ambas plazas, fenómeno que muy marcado en los negocios informales de cuantiles bajos (10 y 25) y en los cuantiles altos (75 y 90) de los formales en la galería Bolívar.

Tabla 3. Modelo log-lin cuantílico de la galería Bolívar. Negocios formales e informales

\begin{tabular}{|c|c|c|c|c|c|c|c|c|c|c|c|c|}
\hline \multirow{2}{*}{$\begin{array}{c}\text { Tipo } \\
\text { Variable }\end{array}$} & \multicolumn{6}{|c|}{ Informales } & \multicolumn{6}{|c|}{ Formales } \\
\hline & $\mathrm{MCO}$ & 910 & 925 & 950 & 975 & 990 & $\mathrm{MCO}$ & 910 & 925 & 950 & 975 & 990 \\
\hline sexo & $-0,23418^{\cdots}$ & 0,05227 & $-0,16646^{\prime \prime}$ & $-0,21221^{\prime \prime}$ & $-0,24454 \cdots$ & $-0,35339 \cdots$ & $-0,33999^{*}$ & 0,10267 & $-0,21391^{\circ}$ & $-0,57088^{\cdots \cdots}$ & $-0,59429 \cdots$ & $-0,47688^{\prime \prime}$ \\
\hline edad & $-0,01068^{\cdots}$ & $-0,00960^{\circ *}$ & $-0,00795^{\cdots}$ & $-0,01536^{\cdots}$ & $-0,01186^{\ldots}$ & $-0,00692^{\circ}$ & $-0,01171^{\circ}$ & $-0,0033$ & $-0,00948^{*}$ & $-0,01519^{\cdots}$ & $-0,00794^{\circ}$ & $-0,01065^{\prime \prime}$ \\
\hline reside & $0,61800^{\cdots}$ & $0,54581^{\cdots}$ & $0,81309^{\cdots \cdots}$ & $0,78840^{\cdots \cdots}$ & $0,50664 \cdots$ & $0,46127^{\cdots}$ & $1,12352^{*}$ & $0,76895^{\circ}$ & $0,71436^{\prime \prime}$ & $0,81763^{\cdots} \cdots$ & $0,77885^{\prime \prime}$ & 0,1155 \\
\hline esc & $0,02922^{*}$ & $0,03577^{* \prime}$ & $0,03990^{\prime \cdots}$ & $0,02969^{\prime \prime}$ & 0,01721 & $-0,0059$ & $-0,00121$ & $-0,03077$ & $0,03050^{\circ}$ & 0,01394 & 0,00437 & 0,00709 \\
\hline ss & $-0,03875$ & $-0,19158$ & $-0,16626$ & $-0,17447$ & $-0,01382$ & $0,49671^{\cdots}$ & $0,49856^{\prime \prime}$ & 0,1677 & 0,32912 & $0,28119^{\circ}$ & $0,62152 \cdots$ & 1,14481'” \\
\hline acteconeg & $0,42892 \cdots$ & 0,09884 & $0,36040 \cdots$ & $0,37156^{\cdots}$ & $0,4496 \mathrm{I}^{\cdots}$ & $0,47612^{\cdots}$ & $1,24289^{\cdots \cdots}$ & $1,57682^{\cdots}$ & $1,74166^{\cdots}$ & $1,19986^{\cdots}$ & $0,67838^{\cdots \cdots}$ & $-0,07192$ \\
\hline diasem & $-0,62299^{\prime \cdots}$ & $-0,66988^{\cdots \cdots}$ & $-0,65500 \cdots$ & $-0,63626^{\prime \cdots}$ & $-0,60672 \cdots$ & $-0,63220^{\cdots \cdots}$ & 0,17371 & $-0,30569^{\circ}$ & $0,20466^{\circ}$ & $0,20966^{\prime \prime}$ & $0,19708^{\circ}$ & $0,35478^{\cdots *}$ \\
\hline maymin & $-0,73338^{\prime \cdots}$ & $-0,32425^{\circ}$ & $-0,35100^{\prime \prime \prime}$ & $-0,77493^{\cdots \cdots}$ & $-0,96375 \cdots$ & $-0,90073^{\cdots \cdots}$ & 0,29063 & $1,15559^{\cdots \cdots}$ & $0,65454^{\cdots \cdots}$ & $0,25196^{\prime \prime}$ & 0,14096 & $-0,59024^{\prime \prime}$ \\
\hline regcont & $-0,63249^{\cdots}$ & $-0,43167^{\cdots}$ & $-0,62937^{\cdots}$ & $-0,67490 \cdots$ & $-0,57662 \cdots$ & $-0,58873^{\cdots \cdots}$ & $-1,01818^{\cdots}$ & $-0,51938^{\prime \prime}$ & $-1,30837 \cdots$ & $-0,75731^{\cdots}$ & $-1,00035 \cdots$ & $-0,96661 \cdots$ \\
\hline area & $-0,00016^{\prime \prime}$ & $-0,0001$ & $-0,00015^{*}$ & $-0,00012$ & $-0,00017^{\prime \prime}$ & $-0,00020^{\circ}$ & $0,00238^{\prime \cdots}$ & $0,00217^{\cdots}$ & $0,00195^{\cdots \cdots}$ & $0,00369^{\cdots}$ & $0,00358^{\cdots \cdots}$ & $0,00271^{\cdots}$ \\
\hline apoyoinst & $0,18117^{* \prime}$ & 0,02855 & 0,06408 & $0,25147^{\cdots}$ & $0,29444^{\cdots \cdots}$ & 0,12849 & 0,14725 & $-0,54144^{\prime \cdots}$ & 0,14471 & $0,16274^{\circ}$ & $0,31460^{\cdots \cdots}$ & 0,03769 \\
\hline org & $-0,05954$ & 0,00175 & $-0,02614$ & $-0,08164$ & $-0,21038^{\prime \prime}$ & $-0,05089$ & 0,3428 & $-0,0099$ & $0,81281^{\cdots}$ & $0,36062^{*}$ & $-0,09666$ & 0,23214 \\
\hline prestamos & $0,58679 \cdots$ & $0,68631^{\cdots}$ & $0,48365^{\cdots \cdots}$ & $0,58319^{\cdots \cdots}$ & $0,54359^{\cdots \cdots}$ & $0,47410^{\cdots}$ & $0,34489^{* \prime}$ & $0,29493^{\circ}$ & $0,28463^{*}$ & $0,24811^{\cdots}$ & 0,04005 & $0,55051^{\cdots}$ \\
\hline subs & $0,16700^{\circ}$ & 0,1827 & $0,15814^{\circ}$ & 0,11654 & 0,12621 & $0,41054 \cdots$ & $-0,22152$ & 0,47039 & 0,01098 & 0,31171 & $-0,83883^{\cdots \cdots}$ & $-0,32249$ \\
\hline const & $16,04627^{\prime \prime}$ & $14,36984^{\cdots \cdots}$ & $14,85457 \cdots$ & $16,17399 \cdots$ & $17,45905 \cdots$ & $17,04455 \cdots$ & 13,76751'” & 13,01612”' & $12,61472 \cdots$ & $13,75847^{\cdots}$ & $15,59116^{\cdots}$ & $16,47233^{\cdots}$ \\
\hline $\mathrm{N}$ & 879 & 879 & 879 & 879 & 879 & 879 & 252 & 252 & 252 & 252 & 252 & 252 \\
\hline r2 & 0,323678 & & & & & & 0,356182 & & & & & \\
\hline$r 2$ p & & 0,15 & 0,191 & 0,1877 & 0,2014 & 0,2137 & & 0,2277 & 0,2004 & 0,2127 & 0,2804 & 0,2924 \\
\hline
\end{tabular}

Fuente: elaboración propia con datos de la Alcaldía Municipal de Popayán.

Donde q: cuantil; MCO: mínimos cuadrados ordinarios; N: número de observaciones; r2: R cuadrado; r2 _ p: Pseudo R cuadrado. 
Claudia Liceth Fajardo Hoyos, Andrés Mauricio Gómez Sánchez y Juliana Isabel Sarmiento Castillo

Tabla 4. Modelo log-lin cuantílico de la galería La Esmeralda. Negocios formales e informales

\begin{tabular}{|c|c|c|c|c|c|c|c|c|c|c|c|c|}
\hline \multirow{2}{*}{$\frac{\text { Tipo }}{\text { Variable }}$} & \multicolumn{6}{|c|}{ Infomales } & \multicolumn{6}{|c|}{ Fomales } \\
\hline & $\mathrm{MCO}$ & $\mathrm{q} 10$ & q25 & 950 & q75 & q90 & MCO & q10 & q25 & 950 & q75 & q90 \\
\hline sexo & $-0,34060^{\circ \cdots}$ & $-0,45019^{\cdots}$ & $-0,33831^{\cdots \cdots}$ & $-0,38010^{\cdots \cdots}$ & $-0,37774 \cdots$ & $-0,24054^{\cdots \cdots}$ & $-0,34367$ & 0,23295 & 0,00659 & $-0,45503^{\cdots *}$ & $-0,81230^{\cdots}$ & $-0,71337^{*}$ \\
\hline edad & $-0,01521^{\cdots}$ & $-0,01896^{\prime \prime}$ & $-0,01415 \cdots$ & $-0,01670 \cdots$ & $-0,01435 \cdots$ & $-0,01207^{\cdots}$ & $-0,01621^{\circ}$ & $-0,01961^{\cdots}$ & $-0,02120^{\prime \cdots}$ & $-0,01786^{\ldots}$ & $-0,01173^{\prime \prime}$ & $-0,01775^{\circ}$ \\
\hline reside & $0,30360^{*}$ & $0,71249^{\cdots}$ & $0,41640^{\cdots}$ & 0,13805 & $0,18542^{* *}$ & $0,23656^{\circ}$ & 0,22571 & $-2,61645 \cdots$ & $-100,654$ & $-0,06563$ & $1,47236^{\prime \prime}$ & 2,29117" \\
\hline esc & 0,0152 & 0,00291 & 0,01971 & $0,02450^{\circ}$ & $0,01852^{\circ}$ & 0,01999 & $-0,02128$ & 0,00745 & $-0,05183^{\circ}$ & $-0,03102^{\circ}$ & $-0,03898^{\circ}$ & $-0,05861^{*}$ \\
\hline ss & 0,1949 & 0,08368 & 0,15075 & $0,31983^{* *}$ & $0,41551^{\cdots}$ & 0,22455 & $-0,59057$ & $-0,36913$ & $-0,19883$ & 0,09873 & $-0,82107 \cdots$ & $-1,50144 \cdots$ \\
\hline acteconeg & $-0,21177^{\prime \cdots}$ & $-0,21008^{\cdots \cdots}$ & $-0,19954$ & $-0,18217^{\prime \prime}$ & $-0,14610^{* \prime}$ & $-0,11623$ & $-0,60788$ & $-1,69794 \cdots$ & $-0,47281$ & $-0,65286^{\circ}$ & $-0,27423$ & $-0,21563$ \\
\hline diasem & $0,46054^{\cdots \cdots}$ & $0,589944^{\cdots \cdots}$ & $0,61120^{\cdots *}$ & $0,53772^{\cdots}$ & $0,22961^{\cdots}$ & $0,18341^{\circ}$ & 0,28006 & $0,36853^{\circ}$ & $0,53522^{*}$ & 0,21718 & 0,09189 & 0,0689 \\
\hline maymin & $-0,34051$ & $-0,04845$ & 0,04335 & $-0,40040^{\circ}$ & $-0,62068^{\cdots}$ & $-0,73850^{\cdots}$ & 0,2751 & $0,64125^{*}$ & $0,68509^{*}$ & $0,69914^{\cdots}$ & 0,39126 & 0,02163 \\
\hline regcont & $-0,39630^{\cdots \cdots}$ & $-0,19931^{\prime \prime}$ & $-0,18565^{\circ}$ & $-0,41714^{\cdots \cdots}$ & $-0,36230^{\cdots \cdots}$ & $-0,58817^{\cdots}$ & $-0,31033$ & $0,34767^{\circ}$ & $-0,12468$ & $-0,37831^{\cdots} \cdots$ & $-0,50381 \cdots$ & $-0,76420^{\cdots}$ \\
\hline area & $-0,00036^{* *}$ & $-0,00005$ & $-0,00015$ & $-0,00040^{*}$ & $-0,00058^{\cdots}$ & $-0,00071^{\cdots}$ & $0,02555^{\circ}$ & $0,03581^{\cdots}$ & $0,01760^{* \prime}$ & $0,01836^{\cdots}$ & $0,02499^{\cdots *}$ & $0,04930^{\cdots \cdots}$ \\
\hline apoyoinst & 0,07176 & 0,09013 & 0,03821 & 0,11067 & 0,00993 & 0,02054 & $-0,00507$ & $-0,58471^{\cdots}$ & $0,36031^{\circ}$ & 0,19125 & 0,05512 & $-0,11916$ \\
\hline org & $-0,06859$ & $-0,08323$ & 0,02829 & $-0,10599$ & $-0,06009$ & 0,05217 & 0,23682 & $0,57033^{*}$ & $0,54875^{\circ}$ & 0,00439 & 0,1996 & $0,56406^{\prime \prime}$ \\
\hline prestamos & $-0,0568$ & 0,04989 & 0,02098 & $-0,0375$ & $-0,04092$ & $-0,37229^{\cdots *}$ & 0,15109 & $0,77356^{*}$ & $-0,32822$ & $-0,05922$ & $-0,26197$ & $0,91725^{*}$ \\
\hline subs & $0,16288^{\circ}$ & $0,21521^{*}$ & 0,10591 & $0,17593^{\circ}$ & $0,23891^{\cdots}$ & 0,07434 & $-0,05494$ & $-0,22661$ & $-0,18146$ & $-0,05988$ & 0,08562 & 0,25309 \\
\hline const & $15,16499 \cdots$ & $13,22632 \cdots$ & $13,82915 \cdots$ & $15,14282 \cdots$ & $16,08614^{\cdots \prime}$ & $17,00099^{\cdots}$ & $14,87426^{\cdots}$ & $14,49751 \cdots$ & $14,83171^{\cdots}$ & $14,85875^{\cdots}$ & $14,27440 \cdots$ & $14,57456^{\prime \prime}$ \\
\hline $\mathrm{N}$ & 785 & 785 & 785 & 785 & 785 & 785 & 80 & 80 & 80 & 80 & 80 & 80 \\
\hline $\mathrm{r} 2$ & 0,2087 & & & & & & & & & & & \\
\hline$r 2 \_p$ & & 0,1733 & 0,1197 & 0,1109 & 0,1021 & 0,1252 & 0,2398 & 0,2331 & 0,1612 & 0,1903 & 0,2217 & 0,3268 \\
\hline
\end{tabular}

Fuente: elaboración propia con datos de la Alcaldía Municipal de Popayán

Donde q: cuantil; MCO: mínimos cuadrados ordinarios; N: número de observaciones; r2: R cuadrado; r2 _ p: Pseudo R cuadrado.

Esto refleja que los negocios de ambas galerías llevan una contabilidad precaria en sus cuentas, lo que puede reflejar informalidad, pero también una forma de evadir impuestos. Por MCO se sobrevalora estos resultados, sobre todo en los negocios informales de la galería La Esmeralda en los cuantiles (10, 25 y 75).

El tamaño o área del establecimiento comercial resulta importante para los establecimientos informales de ambas plazas de mercado, ceteris paribus, con signo negativo preponderantemente en los cuantiles superiores a la mediana. Para los formales también es significativa pero su signo es positivo. Esto refleja que los negocios informales de ambas galerías en su mayoría, ocupan un área reducida y por tanto sus ingresos son acordes al tamaño del negocio y su demanda. Comparado con $\mathrm{MCO}$, sus impactos tienden de nuevo a sobrevalorar los comportamientos en los cuantiles más bajos (10 y 25).

Al analizar las variables institucionales, el apoyo por parte del Estado y la pertenencia a organizaciones sociales sin modificar las restantes variables explicativas, estas se muestran muy poco relevantes. Tan solo en la galería Bolívar en los cuantiles intermedios (50 y 75), ya sea formal o informal el establecimiento. Para La 
Variables asociadas al comportamiento de los ingresos por ventas en las principales plazas de mercado de Popayán, Colombia

Esmeralda, la mayoría de los parámetros no son significativos desde el punto de vista estadístico y los que sí lo son, tienen el signo contrario, lo cual resulta contra intuitivo. Mediante MCO solo resulta ser significativo para los establecimientos informales de la galería Bolívar, pero subvalora su influencia comparado con los cuantiles intermedios.

Los préstamos a entidades financieras como los bancos muestran una elevada significancia en los negocios formales e informales, sobre todo en la galería Bolívar. Esto va en contra de la hipótesis inicial, ya que se sospechaba que las barreras al crédito formal para negocios informales harían recurrir a créditos como el gota a gota. Bajo condiciones ceteris paribus, la galería Bolívar muestra que los ingresos por ventas se elevan fuertemente en todos los cuantiles, especialmente en el cuantil (10) de los informales y en el (90) de los formales. Así, pedir préstamos en los bancos comerciales genera tasas de crecimiento positivas en los ingresos por ventas de los negocios en promedio cercanos al 35\% con todo lo demás constante, tal vez porque estas inyecciones de recursos implican poder expandir o pagar deudas. En La Esmeralda hay mayor incidencia directa en esta variable, en los negocios formales del cuantil 50, con cambios relativos cercanos al 65\%. Mediante MCO no hay incidencia en la galería Bolívar, pero sobrevalora los cuantiles bajos de los negocios informales y los altos de los formales.

Finalmente, los subsidios del Estado tienen una incidencia positiva en los ingresos por ventas para ambas plazas, pero solo para los negocios informales, dejando todo lo demás constante. En los cuantiles 25 y 90 de dichos negocios es que se nota su mayor repercusión. En los demás casos, no resulta ser significativa a lo largo de los cuantiles y cuando lo es, su signo es contrario al esperado. Bajo $\mathrm{MCO}$, el parámetro subvalora fuertemente la tasa de crecimiento en el cuantil 90 de los negocios informales de la galería Bolívar.

\section{CONCLUSIONES Y RECOMENDACIONES}

Las plazas de mercado analizadas son diferentes ya que la galería Bolívar tiene una orientación hacia los negocios pequeños de frutas y hortalizas que coexisten con grandes depósitos de alimentos; mientras que en La Esmeralda los negocios que más ventas registran se dedican más a la comercialización de todo tipo de prendas de vestir y artículos para el hogar. En otras palabras, la plaza de mercado del barrio Bolívar es más una galería y La Esmeralda es más una plaza comercial popular. Esto genera que la formalidad e informalidad no sea igual, pues en la primera la situación es aún más crítica ya que los negocios dependen de una demanda cambiante sujeta a los días y adicionalmente la hora a la que se ofrezcan los productos. En 
La Esmeralda la demanda es más estable en el sentido que venden todos los días, trabajan de 8 a 10 horas en promedio, lo que les facilita una mayor capacidad de asociación gremial y obtener recursos en el sistema financiero.

El modelo de regresión cuantílica captura los diferenciales de tasas de crecimiento del ingreso por ventas en ambas galerías con lo que se evidencia que los aspectos socioeconómicos de los vendedores, en especial el género, juegan un papel importante en todos los cuantiles analizados. Otros aspectos como las características del negocio, en especial la clase de producto ofrecido y el considerarse mayorista o minorista tienen una influencia intermedia, la cual es más marcada en los cuantiles bajos. Finalmente, los aspectos institucionales tienen una incidencia superflua en los ingresos por ventas de los vendedores para amabas galerías en cualquier cuantil, a excepción de la variable que mide el acceso al crédito formal. Los resultados por MCO tienen dos efectos: generalmente sobrevaloran los impactos en los cuantiles bajos (10 y 25) y sobrevaloran los altos (75 y 90); adicionalmente cuando son no significativos, generalmente ocultan alguna relación significativa en un cuantil especifico, lo que sesga el análisis por esta vía.

Como medida, debiese existir una política diferencial por género puesto que las mujeres siempre muestran menores ingresos por ventas, independientemente de si el establecimiento es formal o informal y de la galería que se trate. Una debe centrarse en el apoyo financiero para crear un fondo de trabajadoras cabeza de familia que les permita acceder al crédito de forma rápida y fácil para que no se recurra al crédito gota a gota, con la condición de que se invierta únicamente en el negocio. Otra política debería ser crear una guardería al interior de la galería con subsidio de alimentación para que ellas puedan ampliar sus horarios de trabajo y estar más cerca del cuidado de sus hijos.

Las personas más longevas informales también deben ser protegidas con un proyecto que les permita que sus ingresos no decrezcan con el paso de los años. Los subsidios al adulto mayor deben no solo contemplar beneficios de tipo económico y social, sino también comercial si los ingresos por ventas no superan un salario mínimo mensual legal vigente. El gobierno local debería garantizar una demanda estable a través de la compra de los productos que estos negocios ofrecen para destinarlos a restaurantes caritativos.

Otras medidas serían capacitar a los propietarios en temas contables, administrativos, económicos y financieros para fortalecer sus apuestas productivas, ya que el modelo muestra que la escolaridad es una variable poco relevante a la hora de explicar los ingresos por ventas. Fomentar en los propietarios la participación 
Variables asociadas al comportamiento de los ingresos por ventas en las principales plazas de mercado de Popayán, Colombia

ciudadana en gremios, sindicatos, cooperativas u otro tipo de organizaciones sociales haciéndoles entender que esta fortalece de varias formas sus negocios. Adicionalmente, generar campañas de información sobre todas las ayudas estatales que existen en términos de subsidios y otro tipo de apoyos institucionales que, por falta de conocimiento o ideas erradas sobre los requisitos, no son tomados en cuenta.

Vale la pena también concientizar a los vendedores que formalizarse les permite incrementar la competitividad, sostenibilidad y rentabilidad del negocio. El respaldo institucional es importante ya que se puede gozar de los beneficios que concede el Estado en materia impositiva, se genera un mayor acceso al crédito y se pueden firmar contratos con otros negocios o empresas que requieran sus productos $\mathrm{o}$ servicios. En este mismo sentido, se ha de recordar que, de acuerdo con el modelo las inyecciones de capital están asociadas fuertemente a mayores tasas de ingresos por ventas.

\section{BIBLIOGRAFÍA}

Bayón, Cristina; Roberts, Bryan y Saraví, Gonzalo (1998). Ciudadanía social y sector informal en América Latina. En Perfiles latinoamericanos, Vol. 7, No. 13, diciembre, p. 73-111.

Cade, Brian y Noon, Barry (2003). A Gentle Introduction to Quantile Regression for Ecologists. En: Frontiers in Ecology and the Environment, Vol. 1, No. 8, p. 412-420. doi: https://doi. org/10.1890/1540-9295(2003)001[0412:AGITOR]2.0.CO;2

Coraggio, José Luis (2010). La economía popular solidaria en el Ecuador. Documento de trabajo No. 1, 7p.

Cheng, Gianmarco y Lacroix, Pierril (2014). Ferias y mercados de productos: hacia nuevas relaciones campo-ciudad. Lima, Perú: Centro Peruano de Estudios Sociales, 204p.

Duclos, Mélanie (2017). La (re)socialización desde abajo. Socialidades alternativas y nuevas economías populares en el caso de los mercados de pulgas informales de París, Francia. En: Antípoda Revista de Antropología y Arqueología, No. 29, p. 199-215. doi: http//dx.doi. $\overline{\text { org } / 10.7440 / a n t i p o d a 29.2017 .09 . ~}$

García, Gustavo. (2005). El componente local de la informalidad laboral para las diez principales áreas metropolitanas de Colombia, 1988-2000. En: Desarrollo y Sociedad, No. 56, p. 103-146.

García, Gustavo. (2008. Informalidad regional en Colombia. Evidencia y determinantes. En: Desarrollo y Sociedad, No. 61, p. 43-86.

Gómez, Mauricio; Fajardo, Claudia y Cadena, Olga (2018). Economías populares e inclusión productiva para beneficiarios con vivienda gratuita en Cali, Jamundí y Popayán. En: Cuadernos de Vivienda y Urbanismo, Vol. 11, No. 21, enero, p. 1-19. doi: https://doi.org/10.11144/ javeriana.cvul1-21.epip.

Gutiérrez, Alejandro y Restrepo, Hernando (2002). Trabajo infantil y juvenil en una plaza de mercados de Medellín, año 2000. Revista Cubana de Salud Pública, Vol. 28, No. 3. 
Hurtado, José (2010). El sector informal alimentario en la ciudad de Manizales. Manizales, Colombia: Organización de las Naciones Unidas para la Alimentación y la Agricultura-FAO, 109p.

Hurtado, Olga (2013). Caracterización socioeconómica de la economía popular en la plaza de mercado del barrio "La Esmeralda" en la ciudad de Popayán -Departamento del Cauca. Tesis para optar al título de Economista, Universidad del Cauca, Colombia, 258p.

Julio, Juan Manuel; Rodríguez, Norberto y Zárate, Héctor Manuel (2005). Estimating the COP Exchange Rate Volatility Smile and the Market effect of Central Bank Interventions: A CHARN approach. En: Borradores Banco de la República, Working Papers, No. 347, p. 1-26.

Katz, Jorge y Stumpo, Giovanni (2001). Regímenes sectoriales, productividad y competitividad internacional. En: Revista de la Cepal, Serie 103, No. 75, 60p.

López, Hugo (2010). El mercado laboral colombiano. Tendencias de largo plazo y sugerencias de política. En: Borradores de Economía, No. 606, p. 1-29.

López, Ramiro; Ávila, Adriana y Méndez, Germán. (2011). Dinámica del mercado laboral colombiano: un análisis de políticas de empleo aplicando dinámica de sistemas. En: $9^{\circ}$ Encuentro Colombiano de Dinámica de Sistemas, 14 al 16 de septiembre del 2011, Bogotá, Colombia. Universidad del Rosario.

North, Douglas (1998). Una teoría de la política basada en el enfoque de los costos de transacción. En: La nueva economía política: racionalidad e instituciones. Buenos Aires, Argentina: Edit. Universitaria de Buenos Aires, p. 97-112.

OIT -Organización Internacional del Trabajo (2003). Informe General: Decimoséptima Conferencia Internacional de Estadísticos del Trabajo. Ginebra, Suiza: OIT, 121p.

Ortiz, Carlos Humberto; Uribe, José Ignacio y García, Gustavo Adolfo (2007). Informalidad y subempleo: Un modelo PROBIT bivariado aplicado al Valle del Cauca. En: Revista Sociedad y Economía, No. 13, diciembre, p. 104-131.

Ortiz, Humberto (2002). Economía popular, economía solidaria, fuerza para el desarrollo humano en el Perú. Documento de trabajo, No. 1,7p.

Perea, Alexis (2012). Una alternativa de mercado para las plazas de mercado. Documento de trabajo Bepress, No. 1, 8p.

Pico, Eugenia y Salazar, Myriam (2008). El trabajo infantil como práctica de crianza: contexto de una plaza de mercado. En: Revista Hacia la promoción de la salud, Vol. 13, enero-diciembre, p. $95-120$.

Razeto, Luis (1993). De la economía popular a la economía de solidaridad. México: Instituto Mexicano de Doctrina Social Cristiana. Proyecto de Desarrollo Alternativo, Vol. 34, 47p.

Redacción Bogotá (2013). 'Ser legal a veces cuesta mucho', dice experto en economía popular. José Luis Coraggio cuenta por qué no todo lo informal es malo y cómo podría organizarse. Diario El Tiempo, Bogotá, Colombia.

Rocha, Elisa; Fridman, Igor y Ríos, Esther (2012). Mercados campesinos. Más que un lugar para comprar y vender. Nicaragua: MS-Action Aid, 70p. 
Variables asociadas al comportamiento de los ingresos por ventas en las principales plazas de mercado de Popayán, Colombia

Rojas, Maritza; Vegas, Zulay; Briceño, Leonardo y Rodríguez, Lourdes (2010). Trabajo infantil y salud en un mercado público de Valencia, Venezuela. En: Revista de Salud Pública, Vol.12, No. 1, p. 135-143.

Sarria, Ana Mercedes y Tiriba, Lia (2004). Economía Popular. En la otra economía, Antonio David Cattani (comp. ). Buenos Aires, Argentina: Edit. Altamira, 441p.

Tokdar, Surya y Kadane, Joseph (2012). Simultaneous Linear Quantile Regression: A Semiparametric Bayesian Approach. En: Bayesian Analysis, Vol. 7, No. 1, p. 51-72. doi:10.1214/12-BA702.

Touraine, Alain (1998). De la antigua a la nueva sociología del trabajo. En: Sociología del Trabajo. En: Revista Cuatrimestral de Empleo, Trabajo y Sociedad, Vol. 35, diciembre, p. 3-24.

Vicèns, José y Sánchez, Beatriz (2012). Regresión cuantílica: estimación y contrastes. Madrid, España: Universidad Autónoma de Madrid, No. 21, 28p.

Wooldridge, Jeffrey (2010). Introducción a la Econometría: un enfoque moderno. Ciudad de México, México: Cengage Learning Editores, 865p. 
Claudia Liceth Fajardo Hoyos, Andrés Mauricio Gómez Sánchez y Juliana Isabel Sarmiento Castillo

\section{ANEXOS}

\section{Anexo 1a. Tabla de correlaciones simples para la galería Bolívar}

\begin{tabular}{|c|c|c|c|c|c|c|c|c|c|c|c|c|c|c|c|c|}
\hline & lingv & sexo & edad & reside & esc & ss & acteconeg & diasem & maymin & regcont & otroneg & area & apoyoinst & org & préstamos & subs \\
\hline lingv & 1 & & & & & & & & & & & & & & & \\
\hline sexo & $-0,151$ & 1 & & & & & & & & & & & & & & \\
\hline edad & $-0,1867$ & $-0,0719$ & 1 & & & & & & & & & & & & & \\
\hline reside & 0,3341 & $-0,0661$ & $-0,0508$ & 1 & & & & & & & & & & & & \\
\hline esc & 0,1659 & $-0,0453$ & $-0,245$ & 0,168 & 1 & & & & & & & & & & & \\
\hline SS & $-0,0064$ & 0,1077 & 0,0125 & $-0,0893$ & $-0,0149$ & 1 & & & & & & & & & & \\
\hline acteconeg & $-0,0966$ & 0,0133 & 0,0401 & $-0,3677$ & $-0,1781$ & 0,0472 & 1 & & & & & & & & & \\
\hline diasem & $-0,3009$ & 0,077 & $-0,0426$ & $-0,3074$ & $-0,0997$ & $-0,0179$ & 0,0868 & 1 & & & & & & & & \\
\hline maymin & $-0,2995$ & 0,0739 & 0,0405 & $-0,1636$ & $-0,0219$ & $-0,0088$ & 0,0905 & 0,1796 & 1 & & & & & & & \\
\hline regcont & $-0,4964$ & 0,0511 & 0,1645 & $-0,2225$ & $-0,1544$ & 0,0301 & 0,2509 & 0,2342 & 0,3053 & 1 & & & & & & \\
\hline otroneg & $-0,0226$ & 0,0429 & 0,0381 & $-0,0006$ & 0,019 & 0,032 & $-0,0114$ & $-0,0553$ & $-0,0273$ & 0,0335 & 1 & & & & & \\
\hline area & $-0,0111$ & 0,0152 & $-0,0173$ & $-0,0423$ & $-0,0396$ & 0,0255 & $-0,0446$ & 0,0154 & $-0,0574$ & $-0,0292$ & $-0,0082$ & 1 & & & & \\
\hline apoyoinst & $-0,0139$ & 0,0885 & 0,0249 & 0,0171 & $-0,0624$ & $-0,0067$ & 0,0941 & 0,0159 & 0,0082 & 0,1377 & $-0,0139$ & 0,0051 & 1 & & & \\
\hline org & 0,0337 & 0,0451 & $-0,0181$ & 0,1882 & 0,0209 & $-0,0573$ & $-0,1026$ & $-0,0389$ & 0,0136 & 0,0028 & $-0,0115$ & $-0,0389$ & 0,0231 & 1 & & \\
\hline préstamos & 0,3122 & $-0,0525$ & $-0,0863$ & 0,0831 & 0,0786 & $-0,0126$ & $-0,0679$ & $-0,0779$ & $-0,0562$ & $-0,2938$ & 0,0097 & $-0,0094$ & $-0,0181$ & $-0,052$ & 1 & \\
\hline subs & 0,1509 & $-0,1529$ & 0,0203 & 0,1289 & 0,0807 & $-0,052$ & $-0,1702$ & $-0,1069$ & $-0,0604$ & $-0,1517$ & 0,0486 & $-0,0422$ & $-0,0294$ & 0,0309 & 0,029 & 1 \\
\hline
\end{tabular}

Fuente: elaboración propia

\section{Anexo 1b. Tabla de correlaciones simples para la galería La Esmeralda}

\begin{tabular}{|c|c|c|c|c|c|c|c|c|c|c|c|c|c|c|c|c|}
\hline & lingv & sexo & edad & reside & esc & sS & acteconeg & diasem & maymin & regcont & otroneg & area & apoyoinst & org & préstamos & subs \\
\hline lingv & 1 & & & & & & & & & & & & & & & \\
\hline sexo & $-0,17$ & 1 & & & & & & & & & & & & & & \\
\hline edad & $-0,2236$ & $-0,0675$ & 1 & & & & & & & & & & & & & \\
\hline reside & 0,2541 & $-0,0894$ & 0,0361 & 1 & & & & & & & & & & & & \\
\hline esc & 0,1679 & $-0,0437$ & $-0,3257$ & 0,1412 & 1 & & & & & & & & & & & \\
\hline SS & 0,1493 & $-0,0193$ & 0,0126 & 0,0839 & $-0,0039$ & 1 & & & & & & & & & & \\
\hline acteconeg & $-0,2341$ & 0,08 & 0,0184 & $-0,2296$ & $-0,1291$ & $-0,1293$ & 1 & & & & & & & & & \\
\hline diasem & 0,2587 & $-0,0341$ & 0,0448 & 0,4979 & 0,1012 & 0,0795 & $-0,1553$ & 1 & & & & & & & & \\
\hline maymin & $-0,0784$ & 0,0638 & 0,0902 & 0,1098 & 0,005 & $-0,1188$ & 0,0452 & 0,0424 & 1 & & & & & & & \\
\hline regcont & $-0,2778$ & 0,0764 & 0,1585 & $-0,0966$ & $-0,1439$ & $-0,0663$ & 0,2331 & $-0,0478$ & 0,1677 & 1 & & & & & & \\
\hline otroneg & 0,0247 & $-0,0144$ & 0,009 & 0,0792 & $-0,0249$ & 0,0209 & $-0,0239$ & 0,1547 & $-0,0145$ & $-0,0122$ & 1 & & & & & \\
\hline area & $-0,0629$ & $-0,0497$ & 0,0354 & $-0,0636$ & $-0,0437$ & $-0,0065$ & 0,0284 & $-0,0407$ & $-0,1401$ & $-0,0606$ & 0,0081 & 1 & & & & \\
\hline apoyoinst & $-0,0135$ & 0,0607 & $-0,0066$ & $-0,018$ & $-0,0481$ & $-0,0325$ & 0,0523 & $-0,0444$ & $-0,0068$ & 0,0348 & 0,0235 & $-0,0247$ & 1 & & & \\
\hline org & $-0,0145$ & 0,0163 & 0,0205 & 0,1519 & $-0,0148$ & $-0,0906$ & 0,0207 & 0,092 & 0,0261 & 0,1093 & 0,0792 & 0,0089 & 0,008 & 1 & & \\
\hline préstamos & 0,1939 & $-0,0176$ & $-0,0618$ & 0,0848 & 0,0488 & 0,0448 & $-0,1655$ & 0,1059 & 0,003 & $-0,1659$ & $-0,0547$ & $-0,01$ & $-0,0529$ & $-0,0314$ & 1 & \\
\hline subs & 0,1238 & $-0,1389$ & 0,0333 & 0,1764 & 0,0146 & 0,0721 & $-0,1479$ & 0,1331 & $-0,0048$ & $-0,026$ & 0,0457 & 0,0196 & $-0,0118$ & 0,0118 & 0,0359 & 1 \\
\hline
\end{tabular}

Fuente: elaboración propia 
Variables asociadas al comportamiento de los ingresos por ventas en las principales plazas de mercado de Popayán, Colombia

\section{Anexo 2a. Pruebas estadísticas para el modelo MCO de la galería Bolívar}

\begin{tabular}{|l|c|c|}
\hline \multicolumn{1}{|c|}{ Variable } & FIV & 1/FIV \\
\hline reside & 1,35 & 0,742943 \\
\hline esc & 1,21 & 0,825054 \\
\hline acteconeg & 1,18 & 0,846861 \\
\hline diasem & 1,18 & 0,847265 \\
\hline edad & 1,15 & 0,86994 \\
\hline regcont & 1,13 & 0,887463 \\
\hline sexo & 1,08 & 0,926965 \\
\hline subs & 1,08 & 0,929537 \\
\hline prestamos & 1,06 & 0,939666 \\
\hline org & 1,06 & 0,941627 \\
\hline maymin & 1,05 & 0,949172 \\
\hline ss & 1,05 & 0,954753 \\
\hline apoyoinst & 1,03 & 0,97207 \\
\hline otroneg & 1,03 & 0,975422 \\
\hline area & 1,02 & 0,98232 \\
\hline Media VIF & 1,11 & \\
\hline
\end{tabular}

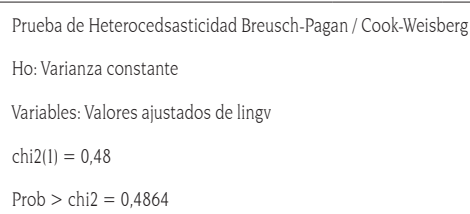

$\begin{array}{lccccc}\text { Prueba de normalidad Shapiro-Wilk } & & & & & \\ \text { Variable } & \text { Obs } & \text { W } & \text { V } & \text { Z } & \text { Prob }>\text { z } \\ \text { Residual } & 1131 & 0,99615 & 2,716 & 2,487 & 0,00645\end{array}$

Pruerba de especificación Ramsey (RESET)

Prueba usando potencias valor ajustado de lingv

Ho: No hay variables omitidas

$\mathrm{F}(3,860)=2,49$

Prob $>\mathrm{F}=0,0554$

Fuente: elaboración propia

\section{Anexo 2b. Pruebas estadísticas para el modelo MCO de la galería La Esmeralda}

\begin{tabular}{|c|c|c|}
\hline Variable & FIV & 1/FIV \\
\hline reside & 1,47 & 0,680526 \\
\hline diasem & 1,40 & 0,714293 \\
\hline esc & 1,21 & 0,82899 \\
\hline edad & 1,19 & 0,839316 \\
\hline regcont & 1,12 & 0,896406 \\
\hline acteconeg & 1,12 & 0,896756 \\
\hline maymin & 1,09 & 0,915523 \\
\hline org & 1,07 & 0,937836 \\
\hline subs & 1,06 & 0,942142 \\
\hline prestamos & 1,05 & 0,948743 \\
\hline otroneg & 1,05 & 0,954597 \\
\hline sexo & 1,04 & 0,957246 \\
\hline area & 1,04 & 0,96219 \\
\hline SS & 1,04 & 0,965191 \\
\hline apoyoinst & 1,01 & 0,986628 \\
\hline Media VIF & 1,13 & \\
\hline
\end{tabular}

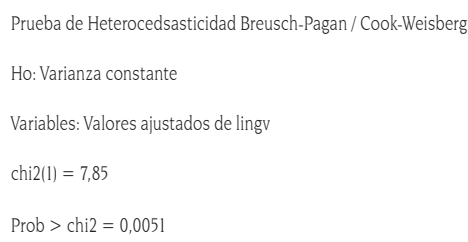

\begin{tabular}{|lccccc|}
\hline Prueba de normalidad Shapiro-Wilk & & & & & \\
Variable & Obs & W & V & Z & Prob $>$ z \\
Residual & 865 & 0,99813 & 1,036 & 0,088 & 0,46508 \\
\hline
\end{tabular}

Pruerba de especificación Ramsey (RESET)

Prueba usando potencias valor ajustado de lingv

Ho: No hay variables omitidas

$\mathrm{F}(3,766)=1,73$

Prob $>\mathrm{F}=0,1588$

Fuente: elaboración propia 